\title{
Análise do conforto ambiental em salas de aula: comparação entre dados técnicos e a percepção do usuário
}

Thermal comfort analysis in classrooms: comparison

between technical data and occupants' perception

\section{J uliana Herlemann Ochoa \\ Daniel Lima Araújo \\ Miguel Aloysio Sattler}

\section{Resumo}

J uliana Herlemann Ochoa Programa de Pós-Graduação em Geotecnia, Estruturas e Construção

Universidade Federal de Goiás Rua Universitária, 1488, Quadra 86,

Lt. Área, Setor Universitáio Goiânia - GO - Brasil CEP 74605-220 Tel.: (62) 3209-6099

E-mail: julianaherlemann@gmail.com

Daniel Lima Araújo

Programa de Pós-Graduação em Geotecnia, Estruturas e Construção

Universidade Federal de Goiás E-mail: dlarauj o@eec.ufg.br

Miguel Aloysio Sattler Núcleo Orientado para a Inovação da Edificação,

Escola de Engenharia Universidade Federal do Rio Grande do Sul Av. Osvaldo Aranha, 99, 30 andar,
Centro

Porto Alegre - RS - Brasil CEP 90035-190

Tel.: (51) 3308-3900

E-mail: masattler@gmail.com

Recebido em 05/04/11

Aceito em 16/02/12

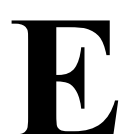

ste trabalho trata da avaliação in loco do conforto ambiental de salas de aula de duas edificações com arquitetura e técnicas construtivas diferentes, que compõe a estrutura da Universidade Federal de Goiás. A pesquisa objetiva explorar essas edificações, buscando identificar a influência das tecnologias construtivas adotadas e da conformação física das mesmas no seu desempenho. Os dados técnicos levantados foram avaliados por modalidade de conforto. No conforto lumínico, realizaram-se medições próximas aos solstícios e equinócios. Os dados de conforto térmico coletados foram a temperatura e a umidade relativa do ar, por um período de onze meses. Já as medições acústicas buscaram a caracterização expedita do clima de rúdos (soundscape) em ambas as edificações, por meio da coleta dos níveis de pressão sonora ocorrentes ao longo de um dia de atividades cotidianas. Notou-se que apesar de as edificações possuírem orientação solar similar, os resultados de desempenho térmico e lumínico dos edifícios foram bastante diferenciados. Paralelamente às avaliações técnicas, foram aplicados questionários aos usuários das salas estudadas, que buscaram caracterizar a percepção destes, em relação a cada uma das modalidades de conforto. Da comparação dos dados técnicos e perceptivos, observou-se que as opiniões dos usuários não foram condizentes com os resultados da análise técnica. Detectou-se divergências entre a proposta de zona de conforto adotada e a satisfação dos usuários das edificações.

Palavras-chave: Conforto Ambiental. Edifícios Escolares. Percepção do usuário.

\section{Abstract}

This paper deals with the on-site evaluation of indoor environmental comfort in classrooms of two buildings at the Federal University of Goiás, characterized by different architecture and construction techniques. This study aims to analyze these buildings in order to identify the influence of the construction techniques and physical conformation on environmental performance. The technical data were collected and analyzed according to the type of comfort. The measurements concerning visual comfort were undertaken around the time of the annual solstices and equinoxes. Indoor microclimatic data, i.e. air temperature and relative humidity, were collected over eleven months. A simplified soundscape characterization was performed with the aid of sound pressure levels, which were collected over a whole day, in the midst of daily activities. It was observed that although the buildings have similar solar orientation, the visual and thermal comfort in these buildings were quite different. In addition to the technical evaluations, questionnaires were also applied to the occupants of the classrooms in order to get their perception for each type of comfort. The comparison of the technical data and the occupants' perception shows that the opinions of the occupants were not consistent with the technical results. A discrepancy was identified between the proposal of comfort zones adopted and the occupants' comfort perception in those buildings.

Keywords: Indoor environmental quality. School Buildings. Comfort Perception. 


\section{Introdução}

A principal função da edificação, escolar ou não, é propiciar a seus usuários proteção e conforto para o desenvolvimento de suas atividades. Essa harmonia no ambiente construído pode ser alcançada por meio do conforto ambiental, de acordo com Corbella e Yannas (2003). Por sua vez, Mendell e Heath (2005) afirmam que a preocupação com a qualidade ambiental nas edificações escolares deve ser uma prática, uma vez que as crianças gastam mais tempo nos ambientes internos da escola do que em sua própria edificação residencial.

Atingir um desempenho ambiental satisfatório envolve um correto planejamento arquitetônico, diante das diferentes condições climáticas que influenciarão nas condições térmicas (temperatura, vento e umidade), na qualidade acústica (proteção de ruídos intrusivos, inteligibilidade do professor pelos alunos e vice-versa) e, ainda, nas condições ideais de visão e iluminação, natural ou artificial, proteção contra poluição e qualidade interna do ar, estabilidade estrutural da edificação, salubridade e higiene, segurança e outros. Losso (2003), por exemplo, aponta diversos estudos que comprovam a importância de aspectos acústicos para propiciar um melhor aproveitamento acadêmico dos estudantes. Já Theodosiou e Ordoumpozanis (2008) realizaram um estudo na Grécia, em escolas (maternais e de ensino fundamental), onde foram analisados o conforto, a eficiência energética e a qualidade interna do ar, através de medições, consumo de energia e questionários. Neste estudo, os autores afirmam que o maior problema encontrado foram as esquadrias, componentes com elevada transmitância térmica, apresentando locais de grande perda de calor devido ao emprego de vidros simples sem a devida vedação. Por sua vez, Li e Tsang (2008) destacam a importância da iluminação natural, particularmente em ambientes escolares, já que ela é considerada a melhor fonte de luz para proporcionar uma boa interpretação das cores, e sua qualidade está diretamente ligada a seu ajuste à resposta visual humana. Adicionam que parâmetros-chave que poderão afetar o desempenho da iluminação no ambiente construído são:

(a) área e orientação da edificação;

(b) área de janelas;

(c) tipo de vidro;

(d) sombreamento; e

(e) obstruções externas.

Normalmente, os estudos desenvolvidos na área de conforto contemplam, de forma mais específica, uma modalidade de conforto, ou seja, avaliações e contribuições são feitas quanto aos parâmetros e requisitos somente no âmbito de térmica, ou da acústica, ou da área de iluminação. Dessa forma, quando se busca trabalhar de forma conjunta $o$ conforto ambiental, abrangendo os três aspectos supracitados, interferências e intersecções entre os requisitos deles ocorrerão naturalmente. Com a presença dessas interferências, não é possível otimizar conjuntamente o conforto térmico, acústico e lumínico. Contudo, Kowaltowski et al. (1999) colocam que é necessária a busca por um conjunto de soluções de compromisso, procurando otimizar esses desempenhos em conjunto. Schmid (2005) vai além afirmando que o conforto ambiental deve ser mais que uma prática, e sim um valor, que, por sua vez, é composto de quatro contextos: físico, psicoespiritual, sociocultural e ambiental.

Xavier (1999) busca estabelecer parâmetros de conforto térmico para estudantes de ensino médio levantando todas as variáveis pessoais dos estudantes participantes em sua pesquisa, incluindo suas sensações e preferências térmicas. Essas variáveis, determinantes para a pesquisa, podem ser afetadas direta ou indiretamente por questões que incorporam, também, outras modalidades de conforto. Por exemplo, a percepção do usuário em analisar isoladamente aspectos ligados ao conforto térmico pode ser influenciada indiretamente por agentes globais de conforto.

Por essa razão, a análise do conforto ambiental por meio apenas da percepção do usuário apresenta limitações por ser uma avaliação basicamente qualitativa. Entretanto, ela é de fundamental importância para validar as análises quantitativas obtidas de medições técnicas, tendo em vista que o objetivo dessas medições é determinar parâmetros ambientais que permitam classificar o nível de conforto de uma edificação, o que, em última instância, depende da satisfação do usuário dela. Dessa forma, ferramentas relacionadas à avaliação pós-ocupação de edificações (ORNSTEIN; ROMERO, 1992) tornam-se muito úteis para a determinação do nível de conforto ambiental proporcionado por uma edificação.

O cruzamento das informações sobre a satisfação do usuário com o ambiente em que vive e os dados obtidos de medições técnicas constitui um recurso de fundamental importância para efetuar-se uma análise crítica das condições de conforto sugeridas por diversas pesquisas e normas internacionais. Afinal, como sugere Szokolay (1980), é normal ocorrer um ajuste do organismo dos usuários às 
condições a que eles estão submetidos durante a maior parte do tempo. Segundo essa ótica, Givoni (1998) afirma que pessoas residentes em países de clima quente têm preferência por temperaturas maiores que as recomendadas pelas normas e por pesquisas desenvolvidas em países de clima frio. Essa afirmação, contudo, deve ser analisada com cuidado, haja vista que outros fatores, que não apenas o clima, podem afetar a percepção do usuário com relação ao conforto ambiental. Além disso, como afirmam Becker, Goldberg e Paciuk (2007), estudos demonstram que podem existir divergências entre os valores preditos para a zona de conforto e os valores reais, em função das condições de cada localidade. Ainda, segundo Fransson, Västfjäll e Skoog (2007), as medições técnicas podem falhar na captura de experiências subjetivas de dimensão simples sensorial, justificando a importância de obter-se uma avaliação sob o ponto de vista do usuário no ambiente interno.

Dessa observação surgiu a presente pesquisa, resultado da dissertação de mestrado da autora (OCHOA, 2010), que tem como objetivo principal confrontar os resultados da percepção de usuários de salas de aula com resultados técnicos, obtidos da avaliação do conforto ambiental dessas salas de aula. Para tanto, a amostra da pesquisa foi limitada a quatro salas de aula, de duas edificações de arquiteturas distintas, na Universidade Federal de Goiás, situadas no campus de Goiânia, na qual foi considerada apenas a opinião de alunos do ensino superior. Para a caracterização técnica do conforto ambiental das salas de aula, foram realizadas medições térmicas, acústicas e lumínicas, bem como foi adotada uma zona de conforto proposta na literatura técnica. Já a percepção dos usuários das salas de aula foi determinada por meio de questionários, aplicados em quatro oportunidades distintas, coincidentes com as quatro estações do ano. Como objetivos secundários, essa pesquisa busca explorar as duas edificações, identificando a influência das tecnologias construtivas adotadas em seu desempenho ambiental, bem como avaliar se as salas de aula estudadas atendem aos requistos normativos de conforto térmico e lumínico, principalmente.

\section{Metodologia}

Para a escolha das duas edificações objeto deste estudo, foram considerados o gabarito, a organização funcional, a tipologia arquitetônica e a localização, entre outros, tendo sido escolhidos o Bloco B, da Escola de Engenharia Civil (EEC), ilustrado na Figura 1, localizado próximo ao centro da cidade, e o Bloco da Faculdade de Artes Visuais (FAV), ilustrado na Figura 2, que fica mais afastado do centro da cidade.

\section{Caracterização da arquitetura do Bloco $B$ da EEC}

\section{Localização}

Essa edificação, com dois pavimentos, fica localizada na Praça Universitária, próximo ao centro da cidade, e compõe o conjunto de edificações que integram as escolas de Engenharia Civil e Engenharia Elétrica e da Computação (Figura 3). No andar térreo do Bloco B são ministradas disciplinas do curso de Engenharia Civil. Essa edificação encontra-se localizada à latitude de $16^{\circ} 40^{\prime} \mathrm{S}$ e longitude $40^{\circ} 14^{\prime} \mathrm{O}$ (Figura 4).

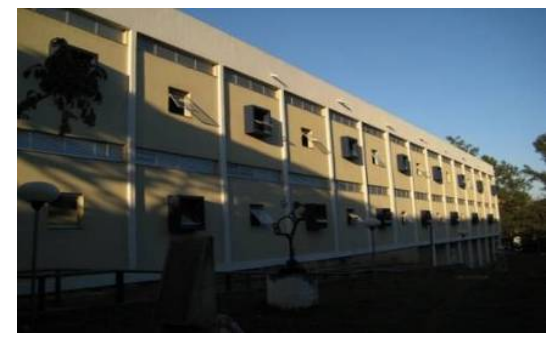

Figura 1 - Escola de Engenharia, Bloco B

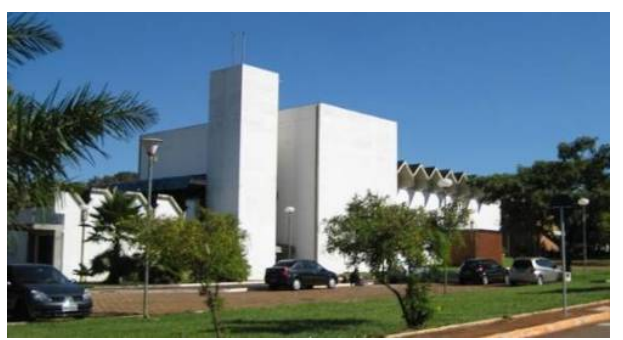

Figura 2 - Faculdade de Artes Visuais 


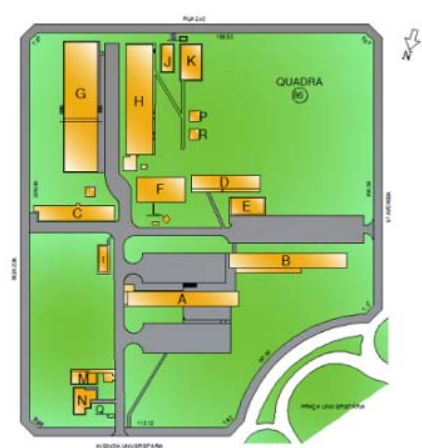

Figura 3 - Implantação geral da Escola de Engenharia

Fonte: Centro de Gestão do Espaço Físico da Universidade Federal de Goiás (2008).

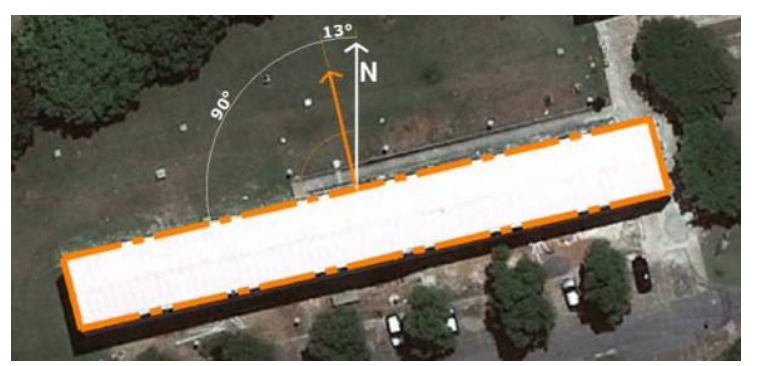

Figura 4 - Orientação solar do Bloco B

Fonte: adaptada de Google Earth (2012).

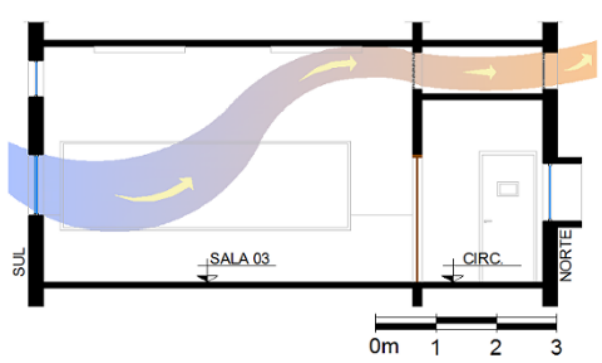

Figura 5 - Sistema de ventilação natural da Sala 3 da EEC

\section{Composição física do edifício}

A estrutura do edifício foi executada em concreto armado, com vedações em alvenaria de tijolos furados. As paredes periféricas são de $25 \mathrm{~cm}$ de espessura, acabadas com reboco e pintura lisa em tinta acrílica, interna e externamente. As paredes internas são de $15 \mathrm{~cm}$ de espessura e também foram executadas em tijolo furado, acabadas com reboco e pintura em tinta acrílica. No interior do edifício, a pintura acontece em duas cores: em tom pastel, até $1,10 \mathrm{~m}$ de altura, com tinta acrílica semibrilho, e acima dessa altura com pintura branco-fosco.

A Sala 3 dessa edificação, escolhida para análise e com dimensões de $6,15 \mathrm{~m} \mathrm{x} \mathrm{8,15} \mathrm{m,} \mathrm{e} 3,88 \mathrm{~m}$ de pé-direito, possui ventilação direta somente pela fachada sul. Nota-se a intenção de ventilar a sala através de efeito chaminé, pois a janela interna da sala abre para uma espécie de duto de ventilação, que tem saída na face externa norte da edificação, vedada com outra janela do mesmo tipo. Ou seja, há um duto que passa sobre o corredor, o qual possui uma laje mais baixa, isolando-o, como ilustrado na Figura 5.

A Sala 6, também escolhida para análise, e com dimensões de $8,25 \mathrm{~m} \times 12,25 \mathrm{~m}$, e 3,88 m de pédireito, possui ventilação cruzada, ocorrente tanto pelas janelas com peitoris menores quanto pelas janelas altas. As janelas na fachada norte existem somente nessa sala e na circulação; alternadamente, possuem brises em seu perímetro.

Todas as superfícies envidraçadas das janelas dessa edificação receberam aplicação de película fumê, fator que reduz consideravelmente os índices de iluminamento no interior das salas. $\mathrm{Na}$ janela mais próxima ao quadro-negro, a película aplicada é opaca, barrando completamente a entrada de luz natural. As janelas altas têm 
persianas metálicas horizontais, na cor azul, em toda sua extensão, que permanecem, na maior parte do tempo, fechadas.

\section{Caracterização da arquitetura do bloco da FAV}

\section{Localização}

Essa edificação localiza-se no Campus II da UFG, na região norte do município de Goiânia, a aproximadamente $8 \mathrm{~km}$ do centro da cidade. Está inserida em uma vizinhança onde há predominância de uso residencial. O edifício da FAV/Emac fica localizado próximo a uma das áreas de preservação permanente do campus, no interior do anel viário dele.

A orientação solar é similar à do Bloco $\mathrm{B}$, da EEC, ou seja, está inclinado $17^{\circ}$ para oeste, em relação ao norte (Figura 6). As fachadas que contêm maior quantidade de aberturas são a norte e a sul, em geral de salas de aulas ou ateliês.

\section{Composição física do edifício}

A estrutura da edificação é toda em concreto armado, com pilares prismáticos, vigas que transpassam as paredes externas do edifício e que ficam expostas nas fachadas, e lajes nervuradas unidirecionais. As paredes periféricas são em tijolo aparente e mantêm esse acabamento, tanto em sua face interna quanto externa. As paredes internas foram executadas em bloco de concreto expandido, e o revestimento é em reboco e pintura lisa, na cor branca. Os pisos são em granitina. Também há brises pintados na cor azul, que são fixados na estrutura do edifício (Figura 7). A cobertura é em laje nervurada unidirecional, de concreto armado, coberta com telha metálica pintada de branco.

As salas estudadas são a 1 e a 3, situadas no bloco de salas da FAV. Elas foram eleitas por possuírem fachada orientada para norte, com a incidência solar mais crítica, diante do clima da região, e também por estarem entre as poucas com aulas no estilo tradicional e não incorporando oficinas ou atividades diferenciadas. Ambas possuem pédireito de $3,20 \mathrm{~m}$, se considerado o ponto mais alto da laje, e 2,80 $\mathrm{m}$ a partir da parte inferior das nervuras da laje. A sala 1 ainda tem o agravante, no tocante às condições acústicas, de fazer divisa com a cantina e estar, assim, mais suscetível aos ruídos ali produzidos.

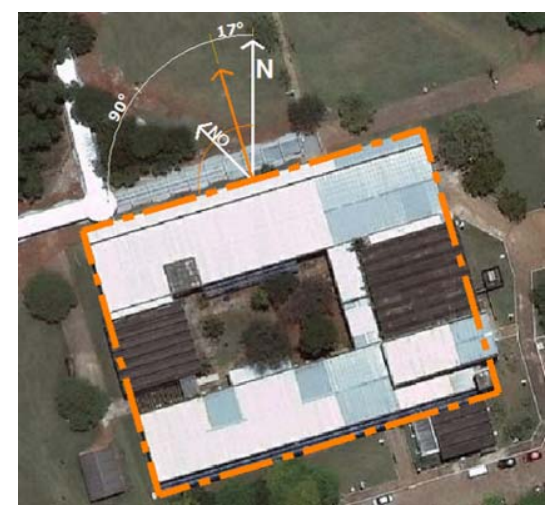

Figura 6 - Orientação solar do Bloco da FAV/Emac

Fonte: Adaptada de Google Earth (2012).

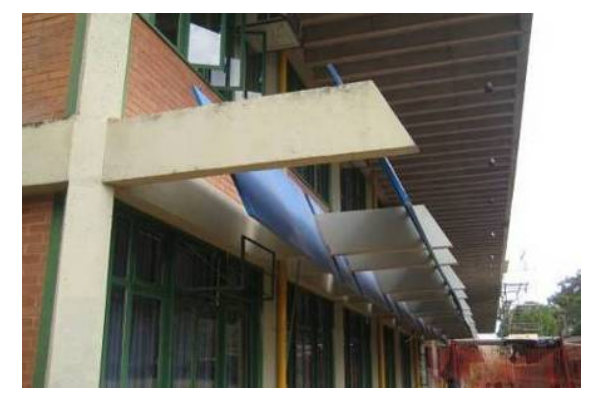

Figura 7 - Brises soleil na fachada norte da FAV 


\section{Instrumentação e parâmetros de avaliação}

$\mathrm{Na}$ fase exploratória da pesquisa foram levantados os registros de arquivos, como o histórico da construção das edificações, os projetos originais e os projetos de reforma, junto ao Centro de Gestão do Espaço Físico (CENTRO..., 2008) da UFG. Antes e durante a pesquisa foi realizada sua observação direta, o que permitiu a coleta de informações sobre vestimentas e hábitos dos usuários e insatisfações relativas ao edifício. Essas informações serviram, por exemplo, como orientadores para a elaboração dos questionários e para a eleição das duas salas estudadas, em cada bloco.

As medições técnicas foram realizadas no período de 24/06/2009 a 01/10/2010, perfazendo mais de um ano de medições. Para essas medições foram adotadas algumas zonas ou limites de conforto. A seguir são descritos esses limites e os equipamentos que foram utilizados para realizar as medições.

\section{Conforto térmico}

Os dados levantados na avaliação de conforto térmico foram a umidade relativa e a temperatura do ar. Ambas foram registradas de hora em hora, por meio de medidores data loggers, da marca Novus, modelo LogBox-RHT-LCD. Esses medidores registram dados de temperatura, com limites entre $-40{ }^{\circ} \mathrm{C}$ e $70{ }^{\circ} \mathrm{C}$ e precisão de $\pm 1{ }^{\circ} \mathrm{C}$; e umidade relativa do ar, entre $0,0 \%$ e $100,0 \%$, com precisão de $\pm 5 \%$. Foram instaladas quatro unidades no Bloco B, da Escola de Engenharia Civil (EEC), sendo um na área externa, um no corredor principal de acesso e um no interior de cada sala de aula monitorada. Na FAV foram instalados outros quatro medidores, sendo dois externos e dois no interior de cada uma das duas salas de aula. As medições foram realizadas sob condições de utilização usuais das salas de aula, buscando registrar as características reais do ambiente em uso.

Para análise dos dados, foi utilizado o diagrama bioclimático para países em desenvolvimento proposto por Givoni (1998). Dessa forma, dados relativos à medição de velocidade do ar, radiação, nível de vestimenta e taxa metabólica, apesar de relevantes para os aspectos de conforto térmico, não foram levantados na pesquisa, por não serem requeridos para o emprego do diagrama bioclimático utilizado. Essa é uma análise limitada, porém compatível com o objetivo da pesquisa, que buscou analisar de forma simples três modalidades de conforto e confrontá-las com a percepção dos usuários. Além disso, como a coleta de dados desenvolveu-se de forma contínua por um ano e considerando o uso dos ambientes, mesmo a temperatura de globo, apesar de relevante, também não foi avaliada. Foi adotado, ainda, como critério adicional de avaliação a quantificação de graus-dia ou graus-hora.

\section{Conforto lumínico}

As medições de iluminância ocorreram em dias próximos aos solstícios de inverno e verão, e aos equinócios de outono e primavera. Foram efetuadas três medições na parte da manhã ( 8 horas, 10 horas, 12 horas) e três no período da tarde (14 horas, 16 horas, 18 horas), seguindo as recomendações da NBR 15215-4 (ABNT, 2005a). A altura de coleta da iluminância foi de $75 \mathrm{~cm}$ acima do piso, que corresponde à altura do plano de trabalho dos alunos (carteiras), mantendo-se o sensor sempre paralelo à superfície avaliada e com o cuidado de evitar que a sombra do operador do luxímetro influísse nas medições.

Para a realização das medições foram utilizados dois luxímetros digitais portáteis, marca Instrutherm, modelo LD-200, calibrados para apresentar uma sensibilidade espectral próxima à curva de sensibilidade do olho humano. Esse equipamento possui uma amplitude de escala entre 0 e 200.000 lux, e sua precisão é de $\pm 3 \%$ para valores abaixo de 10.000 lux e de $\pm 4 \%$ para valores acima de 10.000 lux.

Como limites de conforto, foram utilizados os valores fixados pela NBR 5413 (ABNT, 1992), em que são considerados aspectos como idade dos usuários, velocidade e precisão da tarefa e interferência de refletâncias e contrastes. A norma recomenda um valor mínimo de iluminância de 300 lux nas carteiras dos alunos.

Para cada horário de medição foram calculados a iluminância média ponderada e o fator de uniformidade. Foram, ainda, analisados elementos externos, como as condições da abóboda celeste, condição do entorno e esquadrias. Estas foram avaliadas em função de sua área de iluminação efetiva, dimensão, tipo de vidro e caixilho, com posterior comparação da área da abertura com a área de piso, em cada uma das salas de aula, para verificação do atendimento às exigências do código de obras do município de Goiânia.

\section{Avaliação acústica}

Os níveis sonoros em função do tempo podem ser caracterizados de forma mais concisa por meio de grandezas estatísticas (BISTAFA, 2006). Por meio de um histograma é possível apresentar estatisticamente os níveis sonoros que ocorrem 
dentro de um intervalo de tempo. No entanto, por limitações impostas pelo tipo de equipamento disponível, e para ter alguma caracterização acústica do entorno e interior da escola, optou-se nesta pesquisa por uma caracterização expedita do soundscape local. A intenção desse tipo de levantamento é caracterizar o ambiente acústico natural, que consiste de sons naturais, incluindo vocalizações animais e, por exemplo, os sons associados às condições meteorológicas; e sons ambientais, criados pelos seres humanos e outras atividades ordinárias, incluindo conversação, trabalho e sons de origem mecânica, resultantes do uso de tecnologia industrial. Nesta pesquisa, as medições acústicas foram realizadas durante um dia normal, com as diversas atividades escolares em desenvolvimento. Buscou-se caracterizar o clima de ruídos (soundscape) em vários pontos, distribuídos ao longo das edificações e em seu entorno, que foram escolhidos de modo a representar uma situação ruidosa ou com alguma singularidade importante para a avaliação. Um interessante trabalho nessa área foi a pesquisa interdisciplinar realizada por Irvine et al. (2009), que caracterizaram os soundscapes de três parques em uma cidade do Reino Unido.

Os dados levantados foram de nível de pressão sonora, por período de $5 \mathrm{~min}$, em cada uma das medições. Como equipamento, utilizou-se um medidor de nível de pressão sonora, marca Quest, modelo 1100-20, que atende às Normas ANSI S.1 - 1983 e IEC 651, para o padrão Tipo 2. Tal equipamento permite leitura dos níveis de ruído com resolução de $0,1 \mathrm{~dB}$ e opera medições nas faixas de leitura entre 30 e $100 \mathrm{~dB}, 50$ e $120 \mathrm{~dB}$, e 70 e $140 \mathrm{~dB}$, em curvas de ponderação das leituras em escalas A ou C. Na análise do conforto acústico a avaliação baseou-se apenas no nível de ruído global (em dBA), sem avaliação das bandas de frequências, porque o equipamento disponível para esta pesquisa não permitia uma análise espectral.

Para avaliação do incômodo provocado nos usuários foram observadas as indicações de níveis máximos de ruído, estipulados pela NBR 10152 (ABNT, 1987), que coloca como nível sonoro de conforto, para salas de aula, até $40 \mathrm{~dB}(\mathrm{~A})$, admitindo-se $50 \mathrm{~dB}(\mathrm{~A})$ como nível sonoro aceitável para a finalidade.

\section{Questionários}

Foi realizado um levantamento prévio das disciplinas ministradas nas salas em estudo, bem como do número de alunos matriculados. Desse levantamento, foi estimado o total de usuários de cada sala $(\mathrm{N})$. Usando como base a Equação 1, com um erro amostral de 5\%, foi estimado o tamanho da amostra a ser analisada em cada sala de aula.

$n=\frac{N \cdot n_{0}}{N+n_{0}}$ onde, $n_{0=} \frac{1}{E^{2}}$

Eq. 1

Sendo:

n: tamanho da amostra;

E: erro amostral; e

$\mathrm{N}$ : tamanho da população.

Foi, assim, definida uma amostra de 123 questionários, a serem aplicados aos usuários da sala 3; e 136 questionários para os usuários da sala 6, ambas da EEC. Já na FAV, que possuía uma população menor de alunos e professores, definiuse a aplicação de 29 questionários aos usuários da sala 1 , e 25 questionários aos usuários da sala 3. Parte desses questionários foi aplicada aos usuários das salas no período matutino, e parte, aos do período vespertino, uma vez que as aulas nessas salas ocorriam nos dois períodos.

$\mathrm{O}$ mesmo questionário foi aplicado em todas as salas e abordava questões de conforto térmico, acústico e lumínico, com questões objetivas, de múltipla escolha. Para caracterizar o perfil antropométrico dos usuários, foram levantados dados de sexo e idade. Nas Figuras 8 e 9 são apresentados os resultados do perfil antropométrico dos usuários pesquisados, separados por sala de aula analisada. De forma geral, a maioria dos usuários das salas da EEC era do sexo masculino, enquanto nas salas de aula da FAV houve predominância de usuários do sexo feminino. Com relação à idade, a grande maioria dos respondentes possuía menos de 25 anos.

Esses questionários foram aplicados em quatro períodos diferentes do ano, ao longo de uma ou duas semanas, até que fosse atingida a amostragem preestabelecida, sempre no início de cada estação do ano. Os questionários foram aplicados apenas quatro vezes ao ano, devido ao fato de a temperatura média máxima na cidade de Goiânia, que ocorre por volta das três horas da tarde, variar apenas $3,8{ }^{\circ} \mathrm{C}$ ao longo do ano. Já a temperatura média mínima varia $8,4{ }^{\circ} \mathrm{C}$ ao longo do ano. Entretanto, ela ocorre no final da madrugada, sem a luz do sol, período em que as salas de aula não estão em uso. Dessa forma, já que a variação de temperatura ao longo do ano é pequena, optou-se por aplicar os questionários nos solstícios de inverno e verão, e nos equinócios de outono e primavera, tendo em vista que o sol em Goiânia, no decorrer do ano, modifica consideravelmente seu ângulo de incidência nas fachadas $\left(7^{\circ}\right.$, com a fachada sul, no solstício de verão, e $40^{\circ}$, com a fachada norte, no solstício de inverno). Sendo 
assim, a quantidade de radiação solar que adentra os ambientes varia consideravelmente ao longo do ano (FERNANDES, 2006).

Para a avaliação da percentagem de pessoas insatisfeitas com o ambiente (PPI), as respostas dos usuários foram classificadas em dois níveis: satisfeitos e insatisfeitos. Na Figura 10 é detalhado o questionário aplicado para avaliação da percepção dos usuários com relação às três modalidades de conforto. Nessa tabela, estão marcadas com a cor verde as respostas associadas a usuários satisfeitos, e em laranja as respostas associadas a usuários insatisfeitos. Do ponto de vista do conforto térmico, não foram incluídas perguntas relativas à preferência e à aceitabilidade térmica dos usuários por não serem relevantes ao objetivo da pesquisa.

\section{Resultados das avaliações técnicas}

\section{Análise do projeto arquitetônico}

Inicialmente, foi realizada uma análise do conforto térmico das duas edificações, levando em conta apenas as informações associadas à arquitetura delas, considerando que a edificação deve buscar, desde a fase de projeto, utilizar o mínimo de energia, por meio de técnicas de conservação e princípios de projeto que utilizem estratégias passivas (ROAF; FUENTES; THOMAS, 2006).

Para as salas de aula da EEC, com paredes externas de $25 \mathrm{~cm}$, foram calculados os valores de transmitância térmica, atraso térmico e fator solar, utilizando o software Transmitância (LABORATÓRIO..., 2012). Foi utilizada, ainda, a NBR 15220-3 (ABNT, 2005b), que classifica a cidade de Goiânia na Zona Bioclimática 6 .

A norma recomenda para as edificações da Zona 6 que tenham paredes pesadas. Na Tabela 1 são mostrados os valores de transmitância térmica, atraso térmico e fator solar recomendados e os encontrados para as paredes das salas da EEC. A partir desses valores, pode-se considerar que os índices do bloco de salas de aula da EEC são satisfatórios.

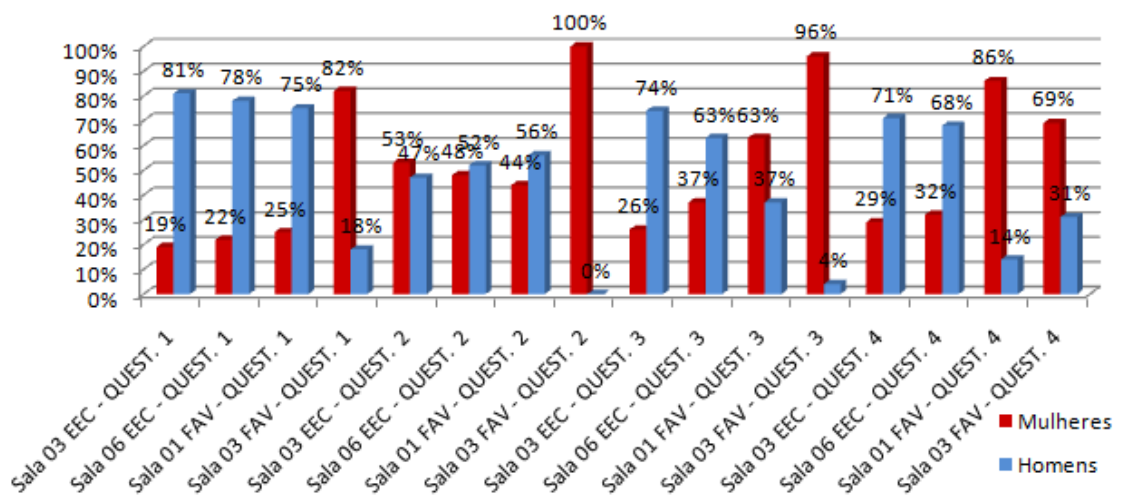

Figura 8 - Perfil do usuário - classificação por sexo

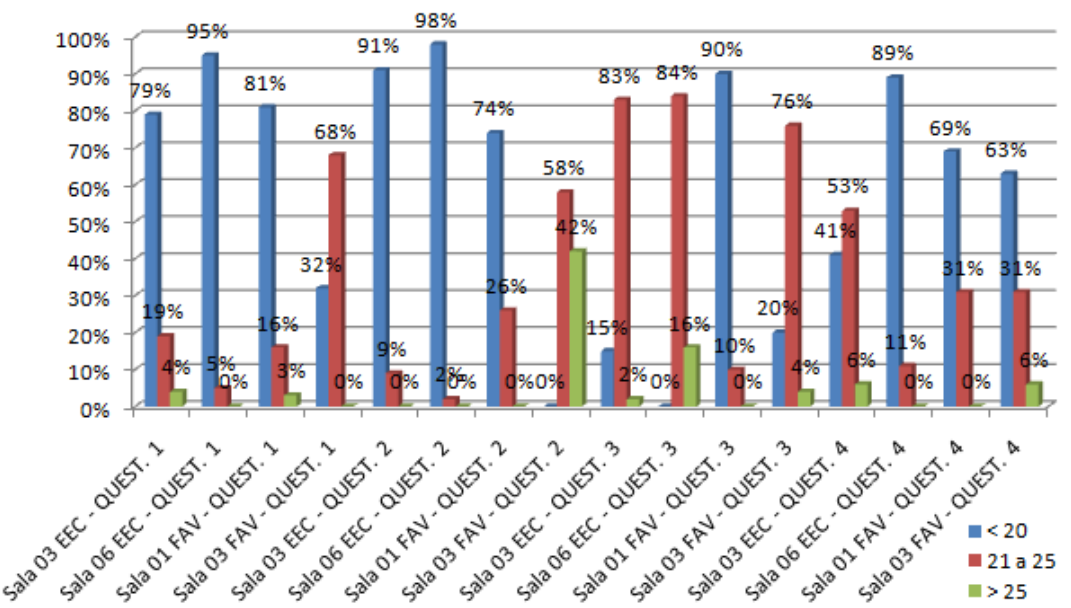

Figura 9 - Perfil do usuário - classificação por idade 


\begin{tabular}{|c|c|c|c|c|}
\hline \multicolumn{5}{|c|}{ QUESTÕES RELATIVAS À TEMPERATURA } \\
\hline \multicolumn{5}{|c|}{1 - Em relação à temperatura como você considera a sala na maior parte do tempo? } \\
\hline Muito Quente & Quente & Confortável & Fria & Muito Fria \\
\hline \multicolumn{5}{|c|}{2 - A ventilação natural (que entra pelas janelas) da sala é para você: } \\
\hline Ótima & Boa & Satisfatória & Ruim & Insatisfatória \\
\hline \multicolumn{5}{|c|}{3 - Com relação ao material em que são confeccionadas as carteiras da sala 03 você pode afirmar que: } \\
\hline \multicolumn{2}{|c|}{ Aumenta o calor } & \multicolumn{2}{|c|}{ É confortável } & $\begin{array}{l}\text { Aumenta o } \\
\text { frio }\end{array}$ \\
\hline \multicolumn{5}{|c|}{4 - Sem o ventilador ligado como considera esta sala? } \\
\hline \multicolumn{2}{|c|}{ Confortável } & \multicolumn{2}{|l|}{ Desconfortável } & \\
\hline \multicolumn{5}{|c|}{5 - A utilização dos ventiladores lhe causa algum incômodo? } \\
\hline \multicolumn{2}{|c|}{$\operatorname{Sim}$} & \multicolumn{2}{|l|}{ Não } & Não sei \\
\hline \multicolumn{5}{|c|}{ 6- Qual tipo de incômodo? } \\
\hline Ruído & Respiratório & Alérgico & \multicolumn{2}{|l|}{ Outro. Qual? } \\
\hline \multicolumn{5}{|c|}{ QUESTÕES RELATIVAS À ILUMINAÇÃO } \\
\hline \multicolumn{5}{|c|}{7 - Como você classifica a iluminação natural nesta sala? } \\
\hline Ótima & Boa & Satisfatória & Ruim & Insatisfatória \\
\hline \multicolumn{5}{|c|}{8 - Como você classifica a quantidade e distribuição das janelas nesta sala? } \\
\hline Ótima & Boa & Satisfatória & Ruim & Insatisfatória \\
\hline \multicolumn{5}{|c|}{9 - Como você classifica a iluminação com luz artificial nesta sala? } \\
\hline 7 Ótima & Boa & Satisfatória & Ruim & Insatisfatória \\
\hline \multicolumn{5}{|c|}{10 - Com que frequência você considera necessário utilizar a iluminação artificial nesta sala? } \\
\hline Sempre & Quase sempre & Freq. Média & Raramente & Nunca \\
\hline \multicolumn{5}{|c|}{11 - Você consegue desenvolver com facilidade todas as atividades sem a luz artificial ligada? } \\
\hline \multicolumn{2}{|c|}{$\operatorname{Sim}$} & \multicolumn{2}{|c|}{ Não } & Não sei \\
\hline \multicolumn{5}{|c|}{12 - Você considera que a instalação de película fumê nas janelas prejudicou a iluminação nesta sala? } \\
\hline \multicolumn{2}{|c|}{$\operatorname{Sim}$} & \multicolumn{2}{|c|}{ Não } & Não sei \\
\hline 13 - Na sua opiniã & intensidade do pre & azido pelo películ & elas? & \\
\hline $100 \%$ & $75 \%$ & $50 \%$ & $25 \%$ & Nenhuma \\
\hline 14 - Você acha qu & s das carteiras dest & acilitam a leitura & & \\
\hline Sim & & Não & & \\
\hline QUESTÕES REL & À ACÚSTICA & & & \\
\hline 15 - Com o ventil & lo você consegue c & m clareza a voz c & sor nesta sala? & \\
\hline Sim & & Não & & Não sei \\
\hline 16 - Em relação à & de e intensidade de & externos nesta sa & você a considera? & \\
\hline Confortável & & Desconfortável & & \\
\hline 17 - Quais os tipo & que geram incôm & & & \\
\hline Tráfego & Alunos externos & Andar Superior & Vento Vegetação & Outros \\
\hline 18 - Você ouve ec & ala? & & & \\
\hline Sim & & Não & & Não sei \\
\hline 19 - Para se ouvir & la é necessário fec & ortas e janelas? & & \\
\hline Sim & & Não & & Não sei \\
\hline 20 - Com que frec & necessário que se & as janelas e porta & ter boa audição? & \\
\hline Sempre & Quase sempre & Freq. média & Raramente & Nunca \\
\hline
\end{tabular}

Figura 10 - Questionário aplicado aos usuários das salas de aula da EEC e da FAV

Tabela 1 - Transmitância térmica, atraso térmico e fator solar - Valores-referência (ABNT, 2005b) e valores levantados na EEC

\begin{tabular}{l|c|c|c}
\hline & $\begin{array}{c}\text { Transmitância térmica }-\mathbf{U} \\
\mathbf{W} / \mathbf{m}^{2} \cdot \mathbf{K}\end{array}$ & $\begin{array}{c}\text { Atraso térmico }-\boldsymbol{\varphi} \\
\text { Horas }\end{array}$ & $\begin{array}{c}\text { Fator solar }-\mathbf{F s}_{\mathbf{o}} \\
\%\end{array}$ \\
\hline Valores recomendados & $\mathrm{U} \leq 2,20 \mathrm{~W} / \mathrm{m}^{2} . \mathrm{K}$ & $\varphi \geq 6,5 \mathrm{~h}$ & $\mathrm{Fs}_{\mathrm{o}} \leq 3,5$ \\
Valores EEC & $\mathrm{U}=1,55 \mathrm{~W} / \mathrm{m}^{2} . \mathrm{K}$ & $\varphi=6,9 \mathrm{~h}$ & $\mathrm{Fs}_{\mathrm{o}}=1,9$ \\
\hline
\end{tabular}


Tabela 2 -Transmitância térmica, atraso térmico e fator solar - Valores-referência (ABNT, 2005b) e valores levantados na FAV

\begin{tabular}{l|c|c|c}
\hline & $\begin{array}{c}\text { Transmitância térmica } \\
-\mathbf{U ~ W} / \mathbf{m}^{2} . \mathbf{K}\end{array}$ & $\begin{array}{c}\text { Atraso térmico }-\boldsymbol{\varphi} \\
\text { Horas }\end{array}$ & $\begin{array}{c}\text { Fator solar }-\mathbf{F s}_{\mathbf{0}} \\
\%\end{array}$ \\
\hline Valores recomendados & $\mathrm{U} \leq 2,20 \mathrm{~W} / \mathrm{m}^{2} . \mathrm{K}$ & $\varphi \geq 6,5 \mathrm{~h}$ & $\mathrm{Fs}_{\mathrm{o}} \leq 3,5$ \\
\hline Valores FAV & $\mathrm{U}=3,86 \mathrm{~W} / \mathrm{m}^{2} . \mathrm{K}$ & $\varphi=2,2 \mathrm{~h}$ & $\mathrm{Fs}_{\mathrm{o}}=10$ \\
\hline
\end{tabular}

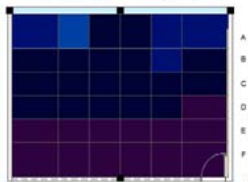

$8 \mathrm{H}$

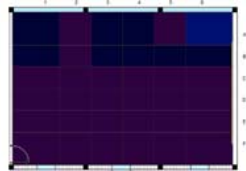

$8 \mathrm{H}$

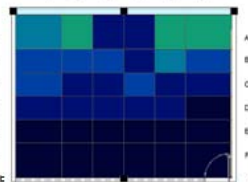

$10 \mathrm{H}$

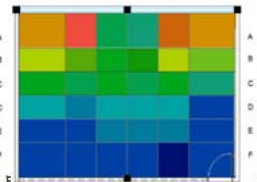

$12 \mathrm{H}$

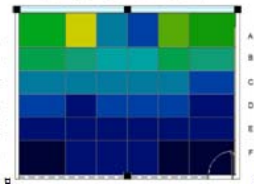

$14 \mathrm{H}$

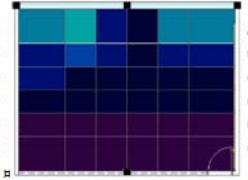

$16 \mathrm{H}$

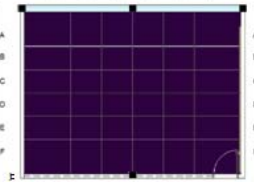

$18 \mathrm{H}$

Mapeamentos de 8 a 18 horas na Sala 3 - Solstício de inverno

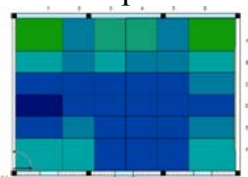

$10 \mathrm{H}$

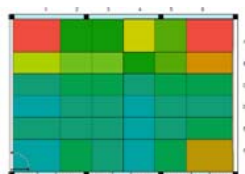

$12 \mathrm{H}$

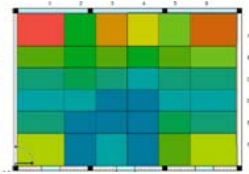

$14 \mathrm{H}$

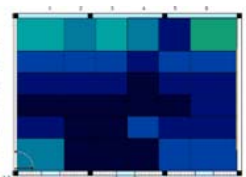

$16 \mathrm{H}$

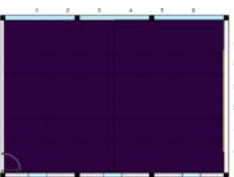

$18 \mathrm{H}$

Mapeamentos de 8 a 18 horas na Sala 6 - Solstício de inverno

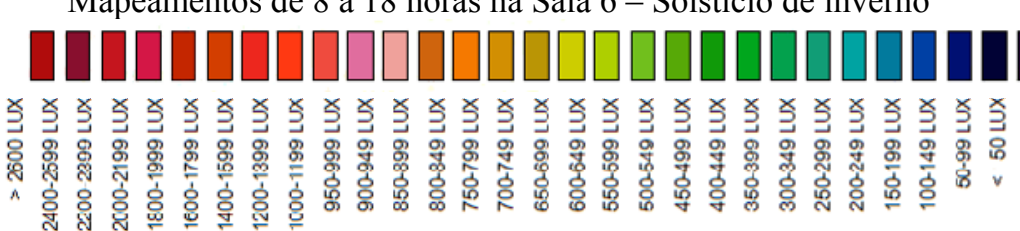

$\sqrt[N]{ }$

Figura 11 - Mapeamentos das salas da EEC, no solstício de inverno, com janelas abertas

Já na Tabela 2 são apresentados os valores de transmitância térmica, atraso térmico e fator solar recomendados e os encontrados para o edifício da FAV/Emac. A partir desses valores, nota-se que nenhum dos índices atende às exigências normativas.

\section{Medições lumínicas}

$\mathrm{Na}$ EEC, ambas as salas, no solstício de inverno, apresentaram resultados insatisfatórios, pois a iluminância média da sala somente superou 300 lux nos horários próximos ao meio-dia. Além disso, foi observada grande variação nos valores de iluminância ao longo da sala, caracterizando um baixo coeficiente de uniformidade. A sala 6 , por possuir aberturas também na fachada norte, obteve melhor desempenho que a sala 3 (Figura 11).

Já no equinócio de primavera e no solstício de verão os resultados das duas salas ficaram equiparados no que diz respeito aos níveis de iluminância média, tendo valores acima de 300 lux, entre $8 \mathrm{~h}$ e $16 \mathrm{~h}$ (Figura 12). Nesses períodos do ano as salas são contempladas por dias mais longos, e o adequado posicionamento das aberturas, na fachada sul, permitiu maior ingresso de luz, apesar da menor incidência solar. Entretanto, o coeficiente de uniformidade ainda foi insatisfatório e bastante variado ao longo do dia. $\mathrm{O}$ máximo valor encontrado não chegou a 0,5 , ou seja, menos de 50\% daquele considerado ideal.

No equinócio de outono foram encontrados os melhores coeficientes de uniformidade para as salas da EEC, que variaram entre 0,35 e 0,57 . Isso demonstra que a orientação das esquadrias para a orientação sul proporciona melhor desempenho ao ambiente, tanto em níveis de iluminância quanto em uniformidade, nesse período do ano.

Nas salas da EEC havia uma película fumê nas esquadrias, o que trouxe grandes prejuízos a seu desempenho em termos de iluminação natural, gerando perdas, principalmente nas áreas próximas a estas, que chegaram a valores de até $80 \%$ (Figura 13). Essa solução tem sido adotada nessas salas para reduzir a iluminância natural nas salas de aula, de modo a serem utilizados equipamentos audiovisuais. Entretanto, o que se observa é uma redução demasiadamente alta, mesmo com as janelas abertas, o que implica o uso contínuo da iluminação artificial nessas salas durante todo o dia. 


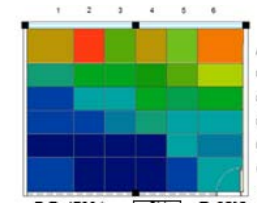

$8 \mathrm{H}$

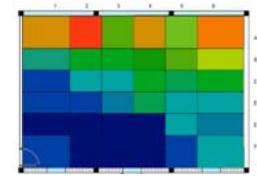

$8 \mathrm{H}$

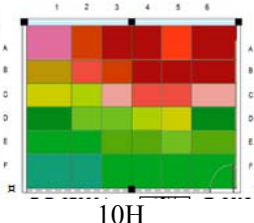

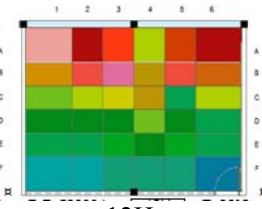

$12 \overline{\mathrm{H}}$

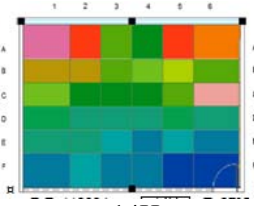

$14 \overline{\mathrm{H}}$

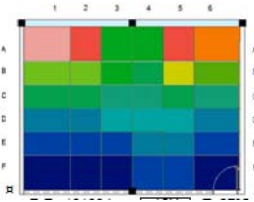

$16 \mathrm{H}$

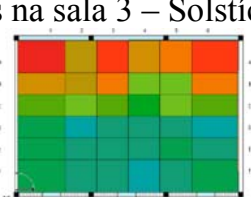

$14 \mathrm{H}$

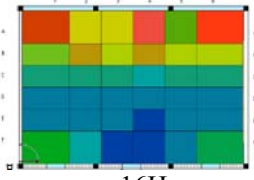

$16 \mathrm{H}$

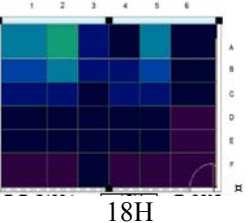

$\overline{18 \mathrm{H}}$

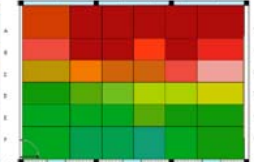

$10 \mathrm{H}$

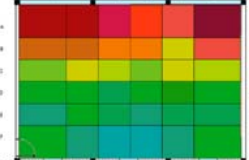

$12 \mathrm{H}$

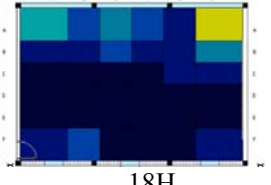

$18 \mathrm{H}$

Mapeamentos de 8 a 18 horas na sala 6 - Solstício de verão

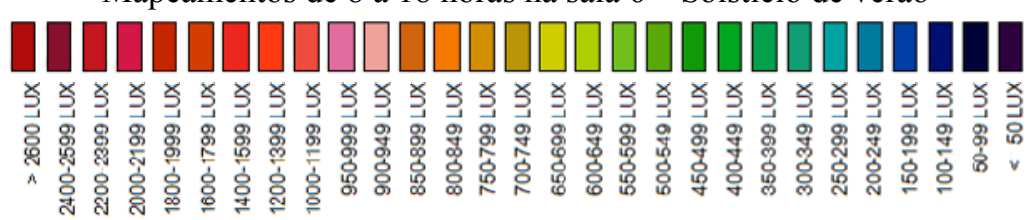

$\sqrt[N]{ }$

Figura 12 - Mapeamentos das salas da EEC no solstício de verão, com janelas abertas

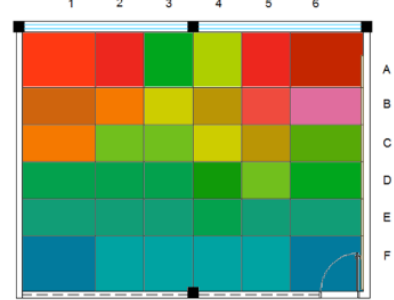

Equinócio de primavera, 14 horas Janelas abertas

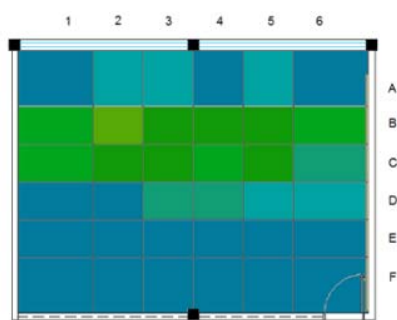

Equinócio de primavera, 14 horas Janelas fechadas

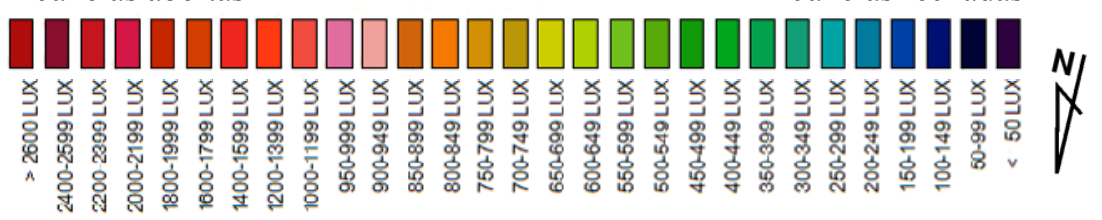

Figura 13 - Medição na sala 3, com janelas abertas e fechadas, às 14 horas do dia 22/09/2009

Nas salas analisadas na FAV, os resultados das medições lumínicas foram próximos e em nenhuma medição alcançaram resultado satisfatório, quando se valendo somente da iluminação natural (Figura 14). Essas salas têm sua iluminação natural barrada, em parte, pelo brise fixo acima das janelas e, também, são sombreadas pela passarela de pedestres externa ao edifício, principalmente durante o inverno (Figura 15). As superfícies internas também são escuras, com pouca refletividade, não colaborando, assim, na melhoria do desempenho lumínico.

A grande variação nos níveis de iluminância, ao longo dos 36 pontos levantados nas salas, leva a um baixo coeficiente de uniformidade, que para essas salas, em nenhum momento, foi superior a $50 \%$ do ideal.
Confrontando os resultados das medições lumínicas das duas edificações, observa-se, que apesar de a edificação da EEC ser de construção mais antiga (1959), ela apresenta um desempenho lumínico superior ao da edificação da FAV, concluída em 1989, mesmo que se valendo da aplicação da película fumê nas janelas. Isso demonstra a influência negativa sobre 0 desempenho lumínico da escolha de elementos arquitetônicos, que visam melhorar o conforto térmico por meio simplesmente da minimização da incidência solar nas janelas, como observado na edificação da FAV. Além disso, mostra como intervenções posteriores no entorno da edificação podem afetar seu desempenho, como é o caso da passarela construída ao lado das janelas da edificação da FAV. 


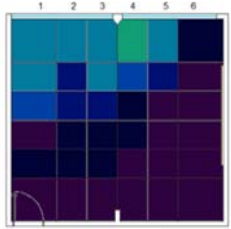

$8 \mathrm{H}$

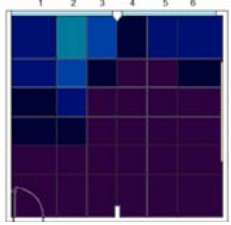

$8 \mathrm{H}$

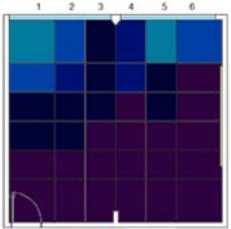

$0 \mathrm{H}$ Mapeamentos de 8 a $12 \mathrm{H}$

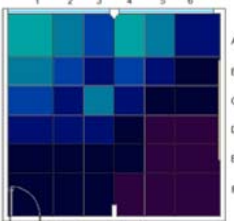

$10 \mathrm{H}$
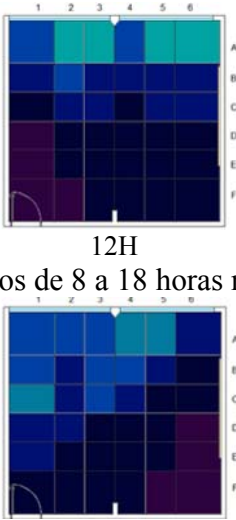

$12 \mathrm{H}$

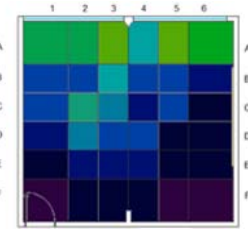

$14 \mathrm{H}$

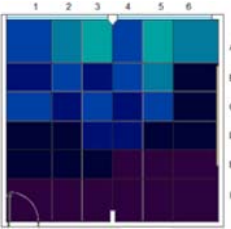

$16 \mathrm{H}$

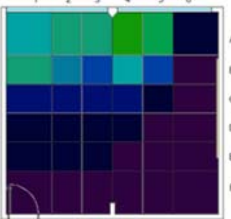

$14 \mathrm{H}$

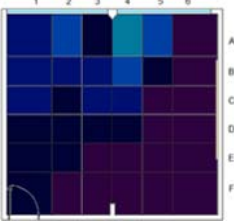

$16 \mathrm{H}$

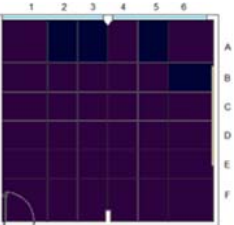

$18 \mathrm{H}$

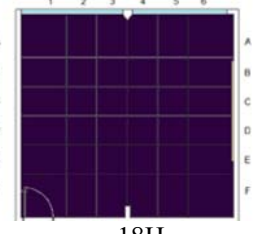

$18 \mathrm{H}$

Mapeamentos de 8 a 18 horas na sala 3 - Equinócio de outono

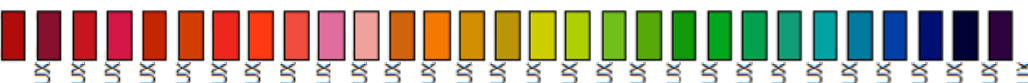

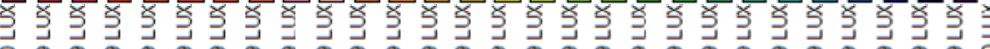

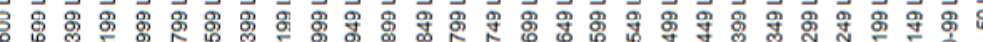

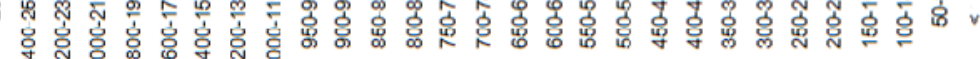

Figura 14 - Mapeamentos das salas da FAV, equinócio de outono

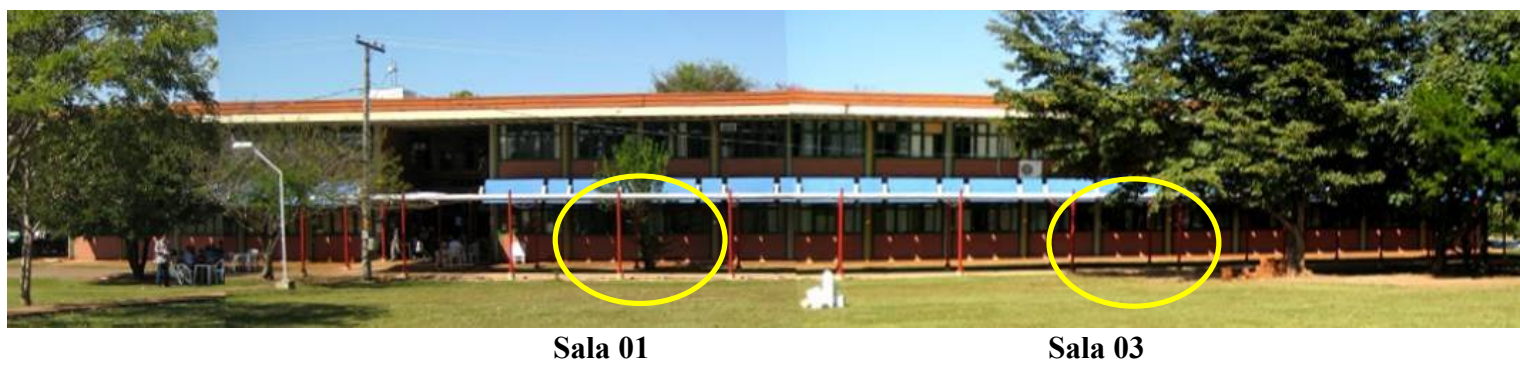

Figura 15 - Panorâmica da fachada norte do edifício da FAV, em 26/06/2009, às 12 horas - Solstício de inverno
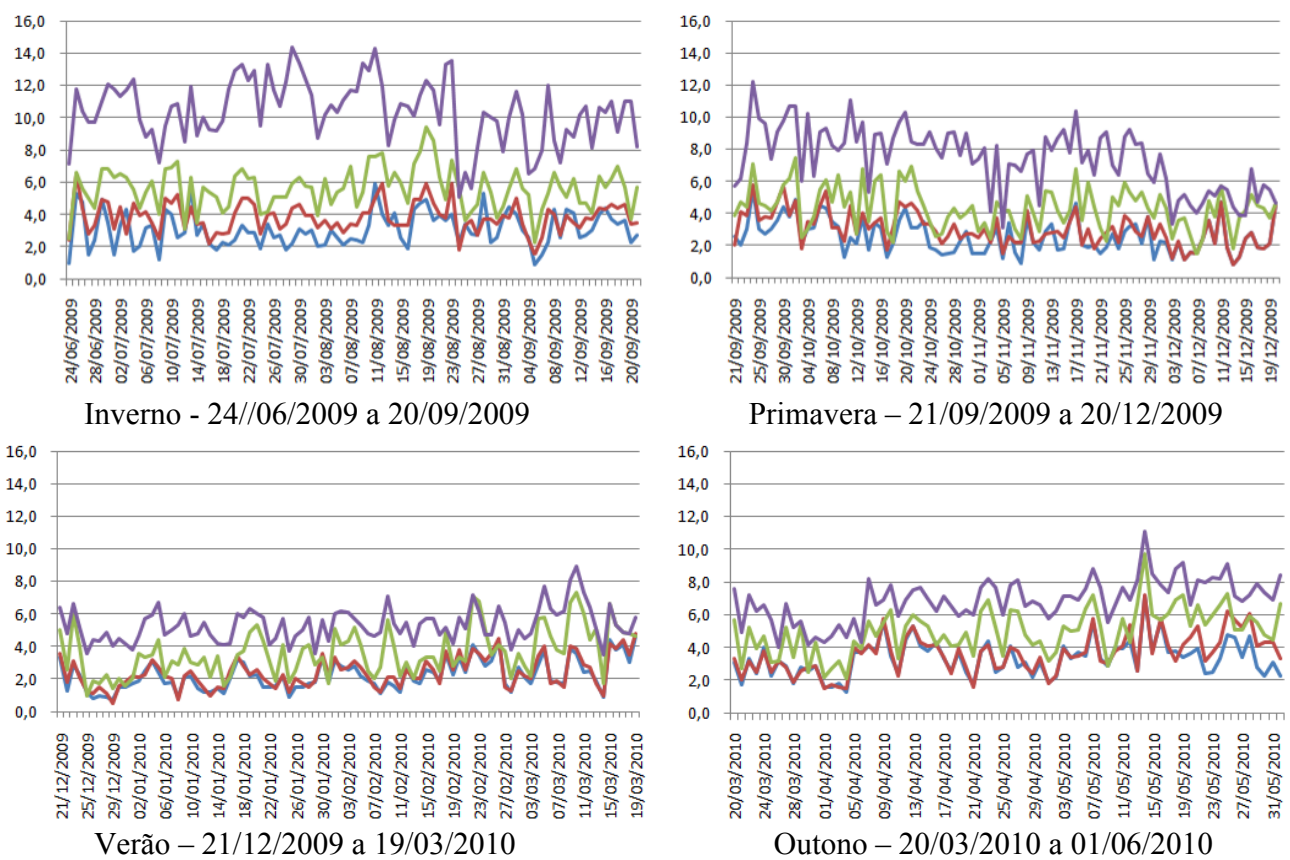

—SALA 03 -SALA06 CIRCULAÇÃO —EXTERNO

Figura 16 - Amplitudes térmicas diárias, por estação do ano, nas salas da EEC 


\section{Medições térmicas}

Mesmo recebendo insolação diferenciada, as duas salas da EEC apresentaram, ao longo do ano, amortecimentos térmicos bem próximos. Os maiores amortecimentos foram registrados durante o inverno $(7,3 \mathrm{~K}$ e $7,8 \mathrm{~K}$ para as salas 3 e 6 respectivamente), o que é positivo, pois essa estação apresenta as maiores amplitudes térmicas (Figura 16). No verão, estação em que as amplitudes são menores, também houve um amortecimento das temperaturas $(6,9 \mathrm{~K}$ e $7,3 \mathrm{~K}$ para as salas 3 e 6 respectivamente).

A partir dos dados horários de temperatura e umidade relativa levantados nas salas da EEC ao longo de um ano, determinou-se a quantidade de horas em que o ambiente térmico dessas salas encontrava-se dentro da zona de conforto. $\mathrm{Na}$ Tabela 3 é apresentado o resultado dessa análise, em forma de porcentuais do período total analisado. Somente a carta psicrométrica trata dos dados de temperatura e UR conjugados. Da comparação dos resultados, nota-se que a porcentagem de dados na zona de conforto é reduzida, quando se consideram as duas variáveis atuando simultaneamente, havendo diferença de $9 \%$, na sala 3 , entre a análise por graus-hora e a análise através da carta psicrométrica. $\mathrm{Na}$ sala 6 , essa diferença foi de $5 \%$.

A partir da faixa de conforto estabelecida para esta análise $\left(18{ }^{\circ} \mathrm{C}\right.$ a $\left.29{ }^{\circ} \mathrm{C}\right)$ e dos resultados da carta psicrométrica, pode-se afirmar que, em $90 \%$ do tempo, as salas da EEC são termicamente confortáveis (Figuras 17 e 18).

\section{Tabela 3 - Resumo de conforto térmico nos ambientes da EEC: percentuais de horas nas zonas de} conforto

\begin{tabular}{c|c|c|c}
\hline Ambiente & Graus-hora (temp.) & Carta psicrométrica & Umidade relativa \\
\hline Sala 3 EEC & $98 \%$ & $89 \%$ & $91 \%$ \\
Sala 6 EEC & $95 \%$ & $90 \%$ & $89 \%$ \\
\hline
\end{tabular}
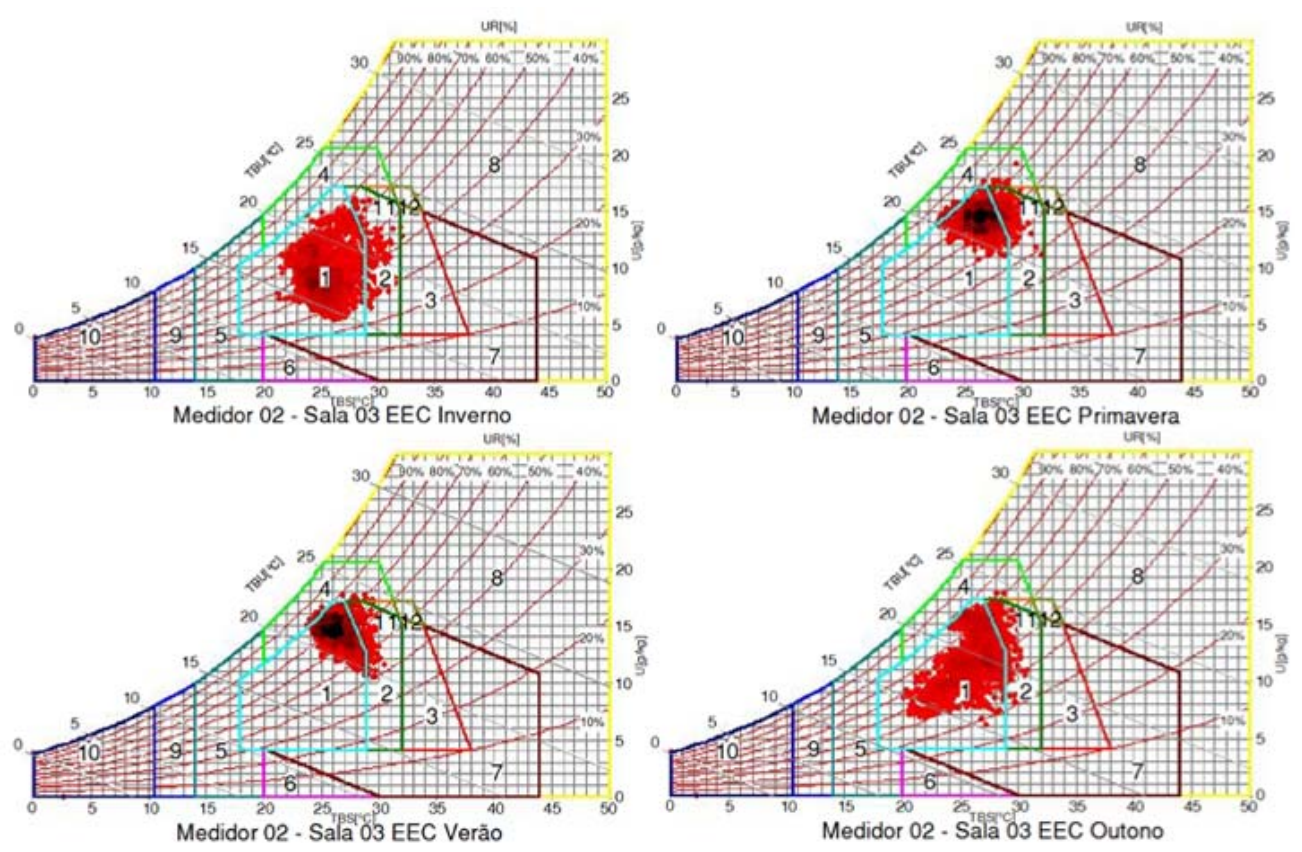

Figura 17 - Cartas psicrométricas relativas à sala 3, EEC

Nota: Legenda:

1 - Zona de Conforto;

2 - Vent./ Massa/ Resf. Evap.;

3 - Massa/ Resf. Evap.;

4 - Ventilação;

5 - Massa Térmica/ Aquec. Solar;

6 - Umidificação;

7 - Resfriamento Evaporativo;

8 - Ar-condicionado:

9 - Aquecimento Solar Passivo;

10 - Aquecimento Artificial;

11 - Ventilação/ Massa; e

12 - Massa térmica p/ resfriamento. 


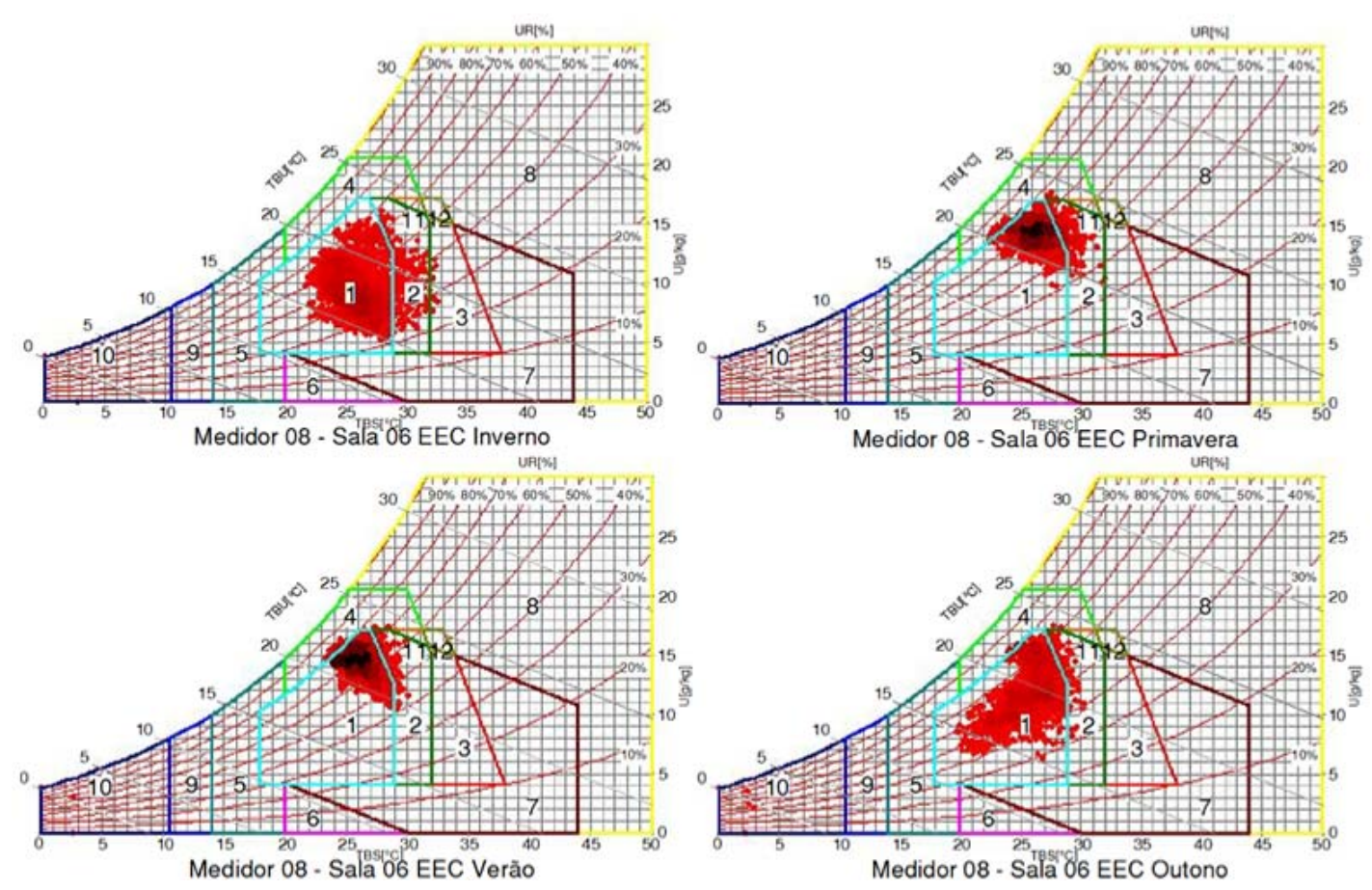

Figura 18 - Cartas psicométricas relativas à sala 6 , EEC

Nota: Legenda:
1 - Zona de Conforto:
2 - Vent./ Massa/ Resf. Evap.;
3-Massa/ Resf. Evap.;
4 - Ventilação;
5 - Massa Térmica/ Aquec. Solar:
6 - Umidificação;
7 - Resfriamento Evaporativo;
8 - Ar-condicionado;
9 - Aquecimento Solar Passivo;
10 - Aquecimento Artificial;
11 - Ventilação/ Massa; e
12 - Massa térmica $p /$ resfriamento.

Tabela 4 - Resumo de conforto térmico nos ambientes da FAV: percentuais de horas nas zonas de conforto

\begin{tabular}{c|c|c|c}
\hline Ambiente & Graus-hora (temp.) & Carta psicrométrica & Umidade relativa \\
\hline Sala 1 FAV & $99 \%$ & $96 \%$ & $94 \%$ \\
Sala 3 FAV & $99 \%$ & $98 \%$ & $97 \%$ \\
\hline
\end{tabular}

Já nas salas da FAV, apesar de ambas possuírem orientação solar semelhante, o comportamento térmico entre elas foi distinto. Os maiores amortecimentos, registrados para a sala 1, foram, em geral, duas vezes maiores que aqueles identificados na sala 3 . A sala 3 caracteriza-se por ficar mais exposta à radiação solar oeste e é a de maior utilização.

Os maiores amortecimentos térmicos, para ambas, foram registrados no inverno: $8,6 \mathrm{~K}$ e $4,8 \mathrm{~K}$ para as salas 1 e 3 respectivamente, o que é positivo, pois essa estação apresenta as maiores amplitudes térmicas. No verão, estação em que as amplitudes são menores, também houve um amortecimento das temperaturas; no entanto, ele é relativamente menor se comparado com o resultado de inverno, 4,3 K e 1,7 K respectivamente.

Na Tabela 4 é apresentada a porcentagem de horas, ao longo do ano, em que essas salas mantêm-se na zona de conforto estabelecida. Novamente, nota-se que a porcentagem de dados na zona de conforto é reduzida quando se consideram as duas variáveis atuando simultaneamente, havendo diferença de $3 \%$ na sala 1 entre a análise por graus-hora e a análise pela carta psicrométrica, sendo essa diferença de $1 \%$ na sala 3 .

A partir da faixa de conforto estabelecida para esta análise e dos resultados da carta psicrométrica, pode-se afirmar que em mais de $90 \%$ do tempo as 
salas da FAV são termicamente confortáveis (Figuras 19 e 20).

Confrontando os resultados das medições térmicas das duas edificações, pode-se concluir que, apesar de ambas apresentarem tipologias arquitetônicas bem distintas, elas possuem bom desempenho térmico. Isso é verdade até mesmo para as salas de aula analisadas na FAV que não atendem aos limites de transmitância térmica, atraso térmico e fator solar, especificados pela NBR 15220-3 (ABNT, 2005b). Para isso deve contribuir, inclusive, a existência de alguns detalhes arquitetônicos, como um jardim no pátio interno. No entanto, provavelmente a principal causa é o grande sombreamento das salas de aula dessa edificação. Dessa forma, o desempenho térmico delas pode ter sido alcançado à custa da penalização de seu desempenho lumínico.

\section{Medições de ruído}

O ruído de fundo, advindo do tráfego urbano, onde se localiza a edificação da EEC, é muito intenso e não encontra barreiras até a edificação. A sala 6 , por estar mais próximo às vias, possui, sem nenhuma atividade, níveis de ruído de fundo que superam o máximo aceitável pela NBR 10152 (ABNT, 1987). Essa característica interfere diretamente no desenvolvimento das atividades nessa sala, exigindo mais esforço de professor e alunos para falar e ouvir com clareza. A sala 3, por estar um pouco mais afastada da extremidade do bloco e ser protegida pelo corredor de acesso, já apresenta níveis de ruído de fundo menores, se comparados aos da sala 6, mas que também superam o máximo aceitável (Figuras 21 e 22).

Já nas salas de aula da FAV, percebe-se que a maior fonte geradora de ruídos são os próprios usuários, enquanto concentrados nas áreas comuns da edificação. A área de preservação, que fica próximo ao edifício, apresenta níveis de pressão sonora, em grande maioria, dentro da faixa recomendada.
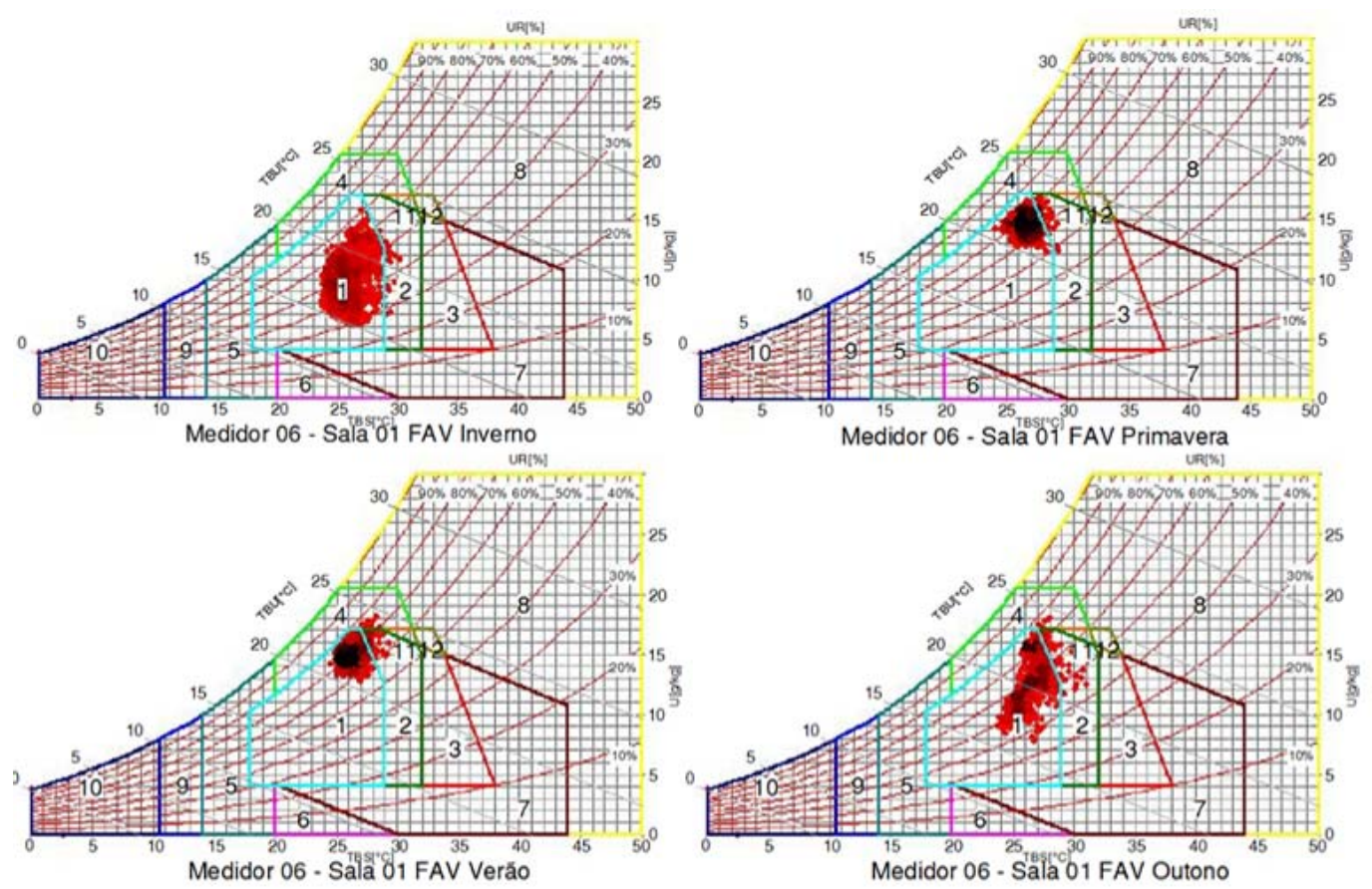

Figura 19 - Cartas psicrométricas, medidor 6, na sala 1, FAV

Nota: Legenda:

1 - Zona de Conforto;

2 - Vent./ Massa/ Resf. Evap.;

3 - Massa/ Resf. Evap.;

4 - Ventilação;

5 - Massa Térmica/ Aquec. Solar;

6 - Umidificação;

7 - Resfriamento Evaporativo;

8 - Ar-condicionado;

9 - Aquecimento Solar Passivo;

10 - Aquecimento Artificial;

11 - Ventilação/ Massa; e

12 - Massa térmica p/ resfriamento. 

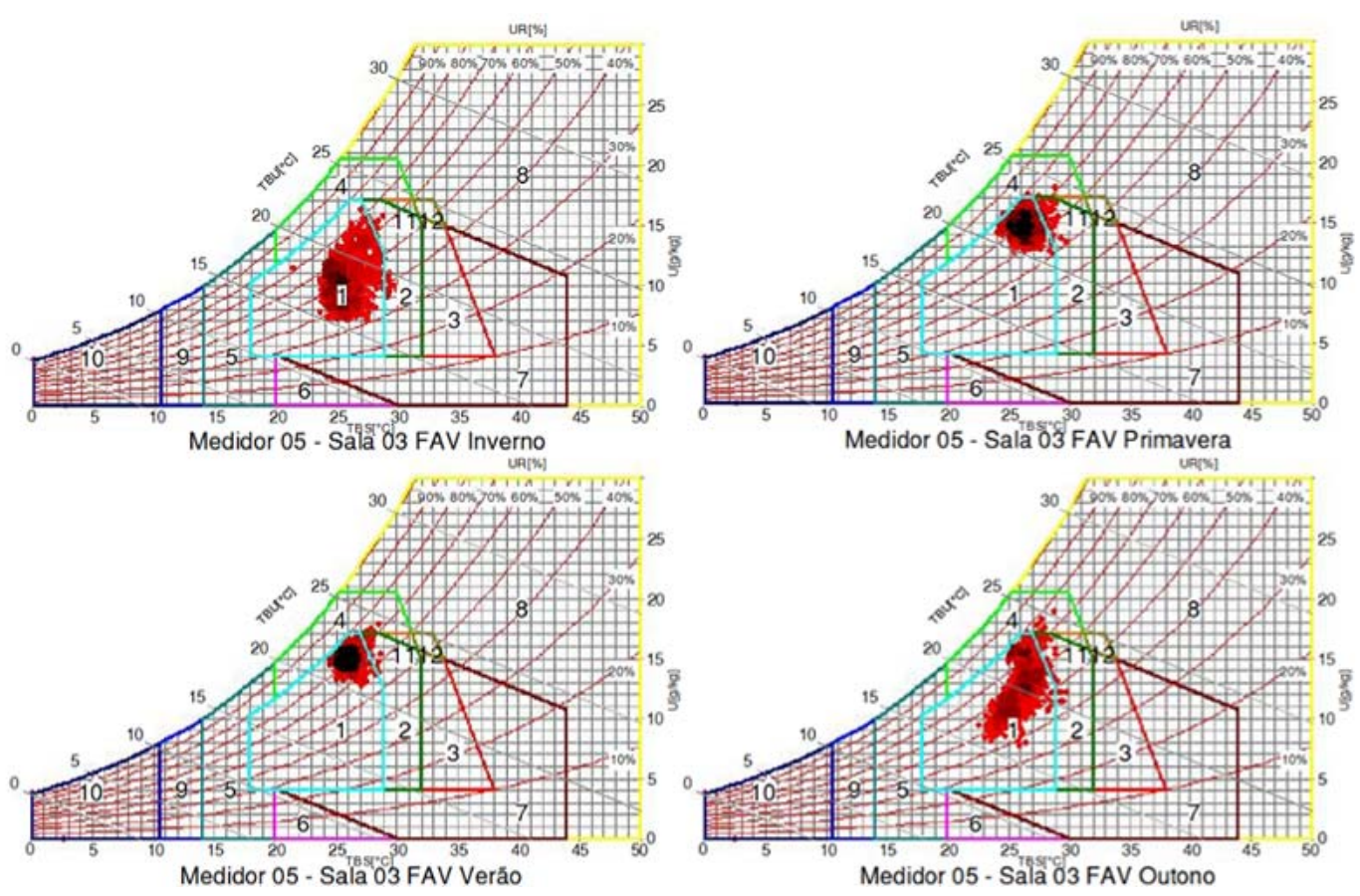

Figura 20 - Cartas psicrométricas, medidor 5, na sala 3, FAV

Nota: Legaenda:

1 - Zona de Conforto;

2 - Vent./ Massa/ Resf. Evap.;

3 - Massa/ Resf. Evap.;

4 - Ventilação;

5 - Massa Térmica/ Aquec. Solar;

6 - Umidificação;

7 - Resfriamento Evaporativo;

8 - Ar-condicionado;

9 - Aquecimento Solar Passivo;

10 - Aquecimento Artificial;

11 - Ventilação/ Massa; e

12 - Massa térmica p/ resfriamento.

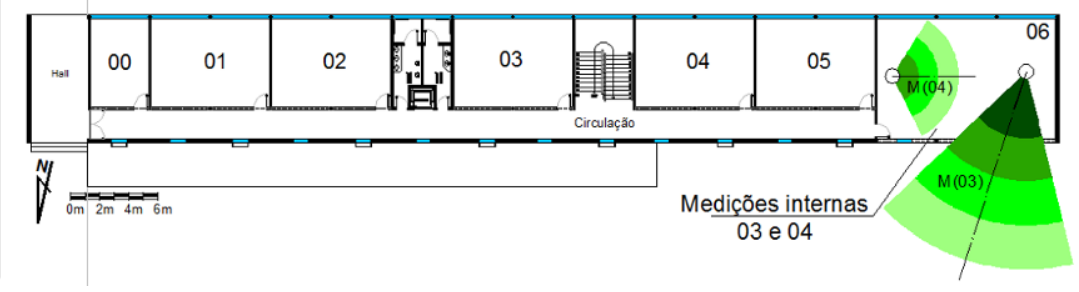

(a) Medições 3 e 4, na sala 6

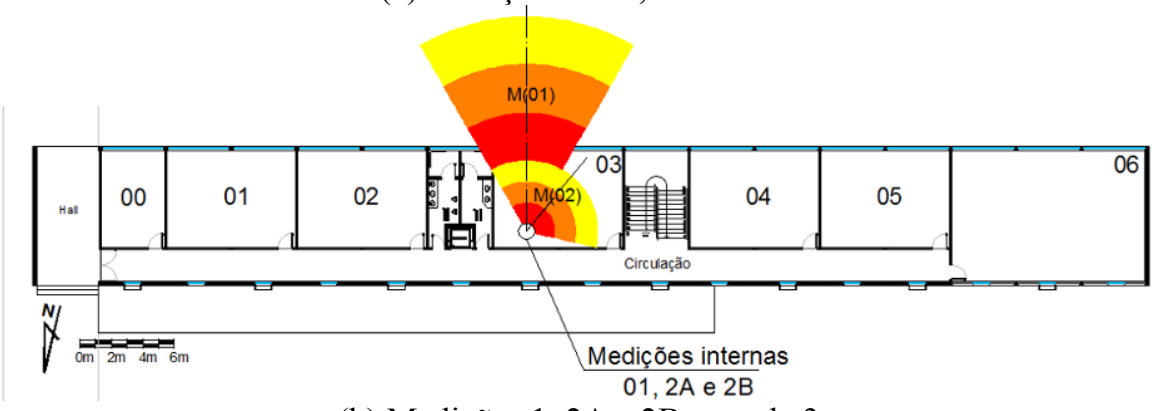

(b) Medições 1, 2A e 2B, na sala 3

Figura 21 - Localização e direcionamento das medições nas salas da EEC 


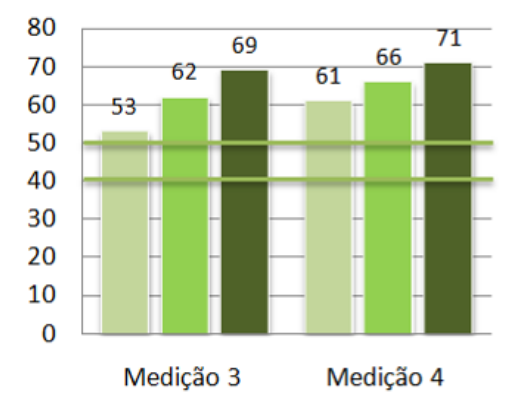

Sala 6

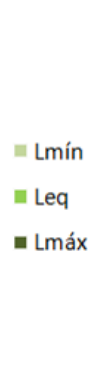

Leq

Lmáx

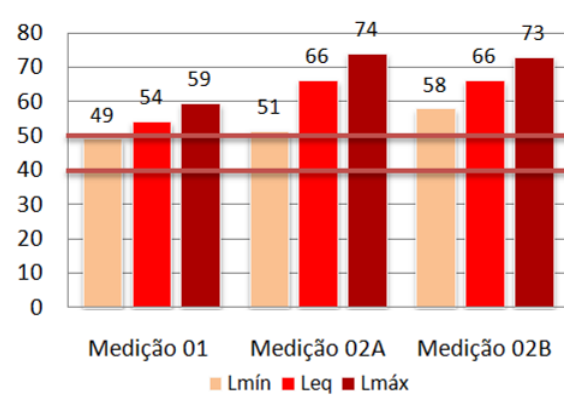

Sala 3

Figura 22 - Níveis de pressão sonora das medições realizadas nas salas da ECC

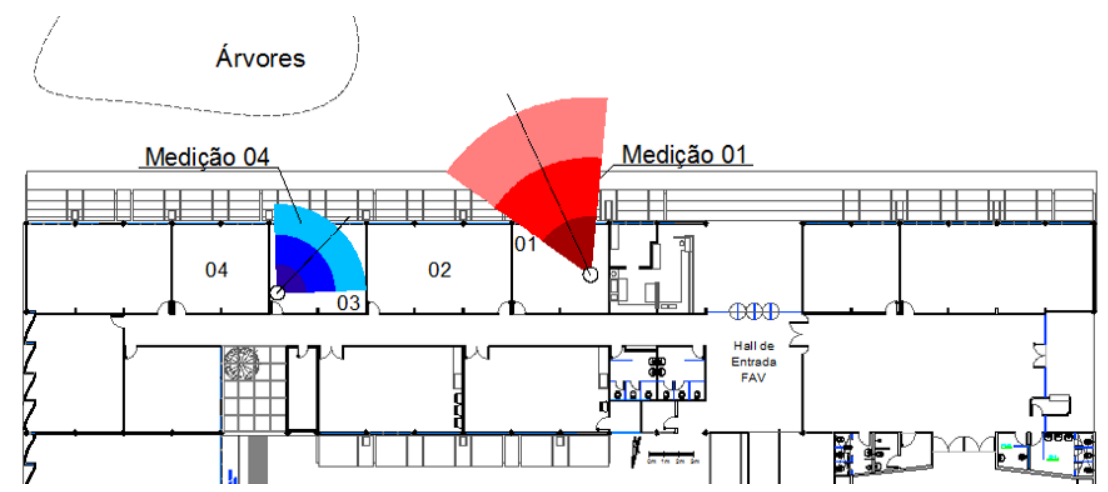

Figura 23 - Localização e direcionamento das medições nas salas da FAV

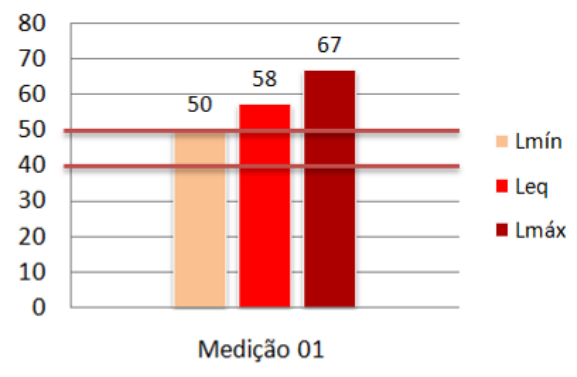

Sala 1

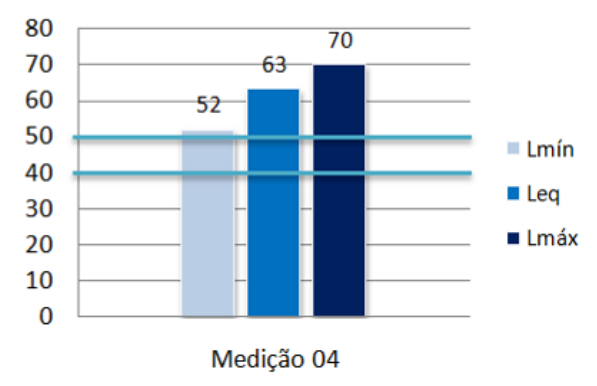

Sala 3

Figura 24 - Níveis de pressão sonora das medições realizadas nas salas da FAV

A sala 1 foi, na ocasião da realização das medições, a mais prejudicada pelos ruídos gerados na lanchonete da FAV, que fica ao lado dela. Com as janelas abertas, os níveis de pressão registrados nessa sala superam, em sua maioria, o limite estabelecido na NBR 10152 (ABNT, 1987). Já a sala 3 está localizada mais distante da lanchonete e, dessa forma, sofre menos interferência dos ruídos desse ambiente. $\mathrm{O}$ ruído que gera incômodo na sala 3, e que supera o limite da NBR 10152 (ABNT, 1987), resulta, em grande parte, da reflexão do som que ocorre na passarela de pedestres e que é fruto da concentração de alunos na circulação e pátio interno do edifício (Figuras 23 e 24).
Dessas medições, pode-se concluir que o principal fator que influencia nos níveis de ruído identificados nas edificações é sua localização. Por estar no centro da cidade, e próxima à via urbana e sem nenhuma barreira física, a sala 6 da EEC apresenta ruídos de fundo muito alto. A solução adotada nessa sala tem sido o fechamento das janelas que dão para a via; entretanto, mesmo assim, o ruído de fundo permanece. Outro problema dessa sala é seu grande volume interno, que, aliado à falta de uma preocupação com as características de absorção de ruído por suas superfícies internas, prejudica em muito seu desempenho acústico, por gerar alta reverberação do som em seu interior. 


\section{Comparação entre os dados técnicos e a percepção dos usuários}

Neste item, procura-se estabelecer uma relação entre os dados técnicos, originários das medições lumínicas, térmicas e acústicas, e os dados perceptivos, advindos do julgamento feito pelos usuários. Para isso, foi levantada em cada estação do ano a porcentagem dos dados técnicos que se encontravam na zona de conforto de cada medição. Esse percentual foi, então, comparado com o percentual de usuários satisfeitos para cada uma das modalidades de conforto analisadas, que pode ser entendido como o complemento da percentagem de pessoas insatisfeitas. A ISO 7730 (INTERNATIONAL..., 2005) parte do pressuposto de uma percentagem de pessoas insatisfeitas (Predicted Percentage of Dissatisfaction - PPD) menor que $10 \%$ como um indicativo de conforto térmico; isto é, pelo menos $90 \%$ das pessoas devem estar satisfeitas para que se possa afirmar que um ambiente é confortável termicamente (LAMBERTS; XAVIER, 2002). Neste trabalho, esse mesmo critério foi aplicado às demais modalidades de conforto, para avaliar-se se o ambiente era confortável do ponto de vista dos usuários.

\section{Conforto lumínico}

Para os dados técnicos, foi calculada a porcentagem de pontos de medição que apresentavam iluminância igual ou superior a 300 lux no plano da carteira dos alunos, admitindo-se que esses pontos estariam na zona de conforto lumínico. Para avaliar a quantidade de usuários satisfeitos foram utilizadas as questões 7, 10 e 11 do questionário mostrado na Figura 10. Apenas os usuários cuja totalidade de respostas encontrava-se no nível satisfeito foram considerados como usuários satisfeitos do ponto de vista lumínico.

$\mathrm{Na}$ Figura 25, onde são comparados os dados técnicos e de percepção dos usuários, observa-se que a percepção dos usuários das salas 3 e 6 da EEC praticamente não se alterou nos quatro questionários aplicados ao longo do ano. Apenas na primavera e no verão o percentual de expressão de satisfação dos usuários dessas salas aproxima-se do percentual de dados técnicos incluídos na zona de conforto. Nos demais períodos do ano, o percentual de usuários que se expressam satisfeitos foi bem maior que o percentual de pontos incluídos na zona de conforto lumínico. Desse resultado, pode-se concluir que as mudanças na indisponibilidade de luz, ao longo do ano, em função da variação climática, não são expressas pelo usuário em termos de sua (in)satisfação com a condição reinante nas salas de aula.

Nas salas da FAV, os resultados do levantamento técnico demonstraram a ocorrência generalizada de baixos níveis de iluminância natural (Figura 26) em todas as estações. Apesar disso, a satisfação dos usuários no tocante à iluminação natural é expressa em níveis, inclusive, bem superiores aos levantados nas salas da EEC. Pode-se inferir que essa discrepância entre os resultados possa ser resultante do tipo de atividade desenvolvida em sala de aula, pois em $90 \%$ do tempo os alunos têm aulas ministradas com auxílio de projetor, o que faz com que o baixo nível de iluminação natural não atrapalhe o adequado desenvolvimento das atividades.

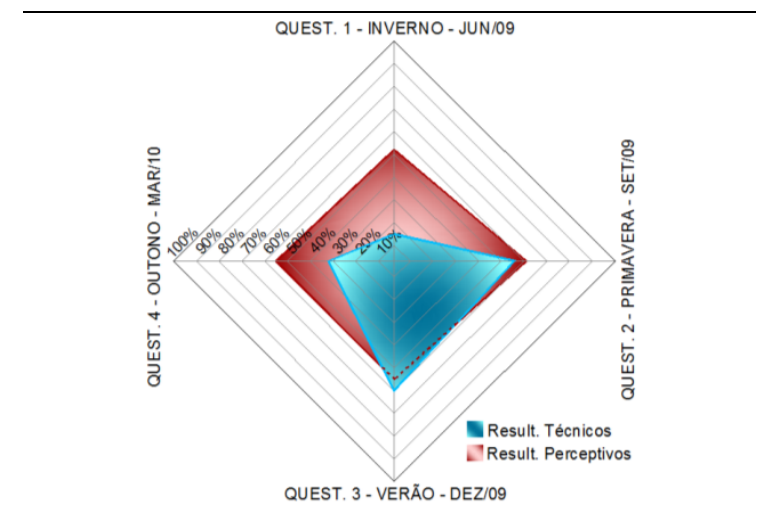

(a) SALA 3 - ESCOLA DE

ENGENHARIA CIVIL

Resultados lumínicos utilizando porcentagem de pontos de medição inseridos na zona de conforto

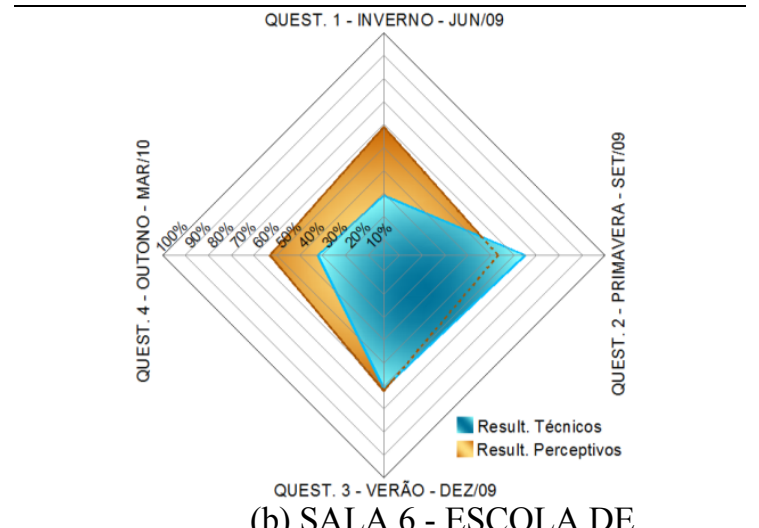

(b) SALA 6 - ESCOLA DE

ENGENHARIA CIVIL

Resultados lumínicos utilizando porcentagem de pontos de medição inseridos na zona de conforto

Figura 25 - Gráficos comparativos entre a percepção dos usuários e os dados técnicos de iluminação natural das salas da EEC 


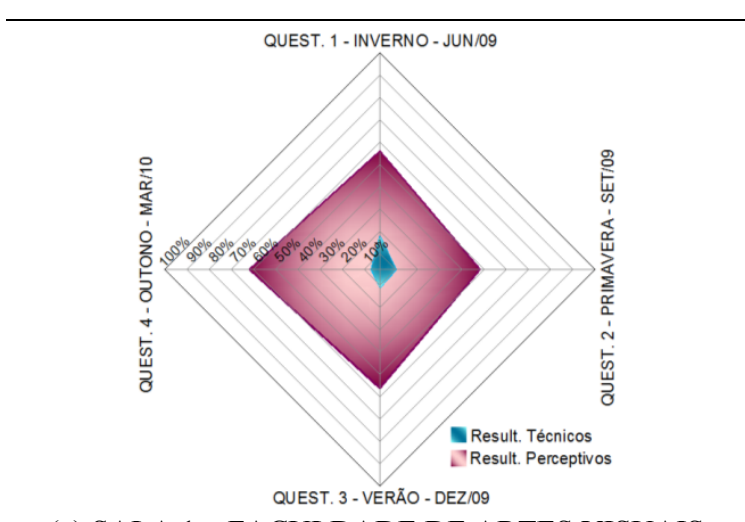

(a) SALA 1 - FACULDADE DE ARTES VISUAIS

Resultados lumínicos utilizando porcentagem de pontos de medição inseridos na zona de conforto

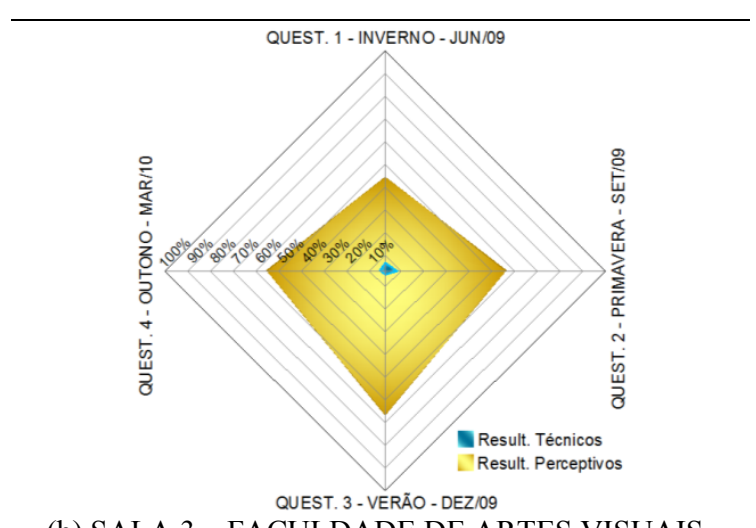

(b) SALA 3 - FACULDADE DE ARTES VISUAIS

Resultados lumínicos utilizando porcentagem de pontos de medição inseridos na zona de conforto

Figura 26 - Gráficos comparativos entre a percepção dos usuários e os dados técnicos de iluminação natural das salas da FAV

Desses resultados, pode-se concluir que, do ponto de vista técnico, as salas em estudo não apresentavam condições desejáveis de conforto lumínico. No entanto, tal condição não é identificada na percepção dos usuários, que, apesar de não se manifestarem plenamente satisfeitos com as condições de iluminação natural, percebem os ambientes das salas de aula bem mais confortáveis que o esperado.

\section{Conforto térmico}

Para a comparação de resultados do conforto térmico do ponto de vista das medições técnicas, foram tomadas apenas as leituras de temperatura e umidade relativa realizadas na semana em que foram aplicados os questionários, em cada uma das salas. Esse intervalo de tempo foi escolhido por considerar-se que possa ter maior influência sobre a opinião dos usuários, como uma forma de memória recente. Para a determinação da porcentagem de horas em que essas salas eram consideradas confortáveis, foi quantificada a quantidade de horas em que a temperatura estava no intervalo admitido como zona de conforto, segundo a carta psicrométrica $\left(18{ }^{\circ} \mathrm{C}\right.$ a $\left.29^{\circ} \mathrm{C}\right)$, sendo esse valor dividido pelo total de horas registradas na semana.

Para avaliar a quantidade de usuários satisfeitos foram utilizadas as questões 1, 2 e 4 do questionário mostrado na Figura 10. Apenas os usuários cuja totalidade de respostas encontrava-se no nível satisfeito foram considerados como usuários satisfeitos do ponto de vista térmico.

Da comparação dos resultados, obtidos pelas duas metodologias, para as salas da EEC, observa-se grande diferença entre os dados técnicos e os dados perceptivos dos usuários, como pode ser visto nas Figuras 27(a) e 28(a).

Em função dessa diferença, foi adotada uma zona de conforto menor, entre $18{ }^{\circ} \mathrm{C}$ e $27{ }^{\circ} \mathrm{C}$, pois se sabe, de modo consensual entre os residentes nessa zona climática, que o maior desconforto ocorrente em ambientes internos é devido ao calor. Os resultados foram novamente confrontados entre si, e o resultado final é ilustrado nas Figura 27(b) e 28(b). Com essa nova zona de conforto, a porcentagem de usuários satisfeitos ficou mais próxima da porcentagem de horas em que as salas apresentavam-se na zona de conforto térmico, sobretudo no outono. Nas demais estações do ano, a satisfação dos usuários foi menor que a porcentagem de horas em que as salas apresentavam-se na zona de conforto, determinada pelos dados técnicos. Essa grande insatisfação dos usuários com relação às temperaturas pode indicar que, mesmo habituados a um clima mais quente, eles não toleram tão bem as temperaturas altas, pois o nível de satisfação aumentou no período do outono, que apresentou temperaturas mais amenas, e diminuiu quando houve temperatura e umidade relativa mais alta, durante a primavera e o verão.

Nas salas da FAV, apesar de a maioria das temperaturas registradas estar inserida na zona de conforto, elas, em geral, são mais altas que aquelas levantadas nas salas da EEC. Talvez por essa razão tenha havido maior discrepância entre a porcentagem de usuários satisfeitos e os dados técnicos, mesmo quando se adotou uma zona de conforto menor (entre $18{ }^{\circ} \mathrm{C}$ e $27^{\circ} \mathrm{C}$ ). Em todas as estações do ano, o nível de usuários satisfeitos com o conforto térmico foi sempre menor que a porcentagem de horas em que a temperatura nas salas encontrava-se na zona de conforto, segundo as medições técnicas (Figuras 29 e 30). 


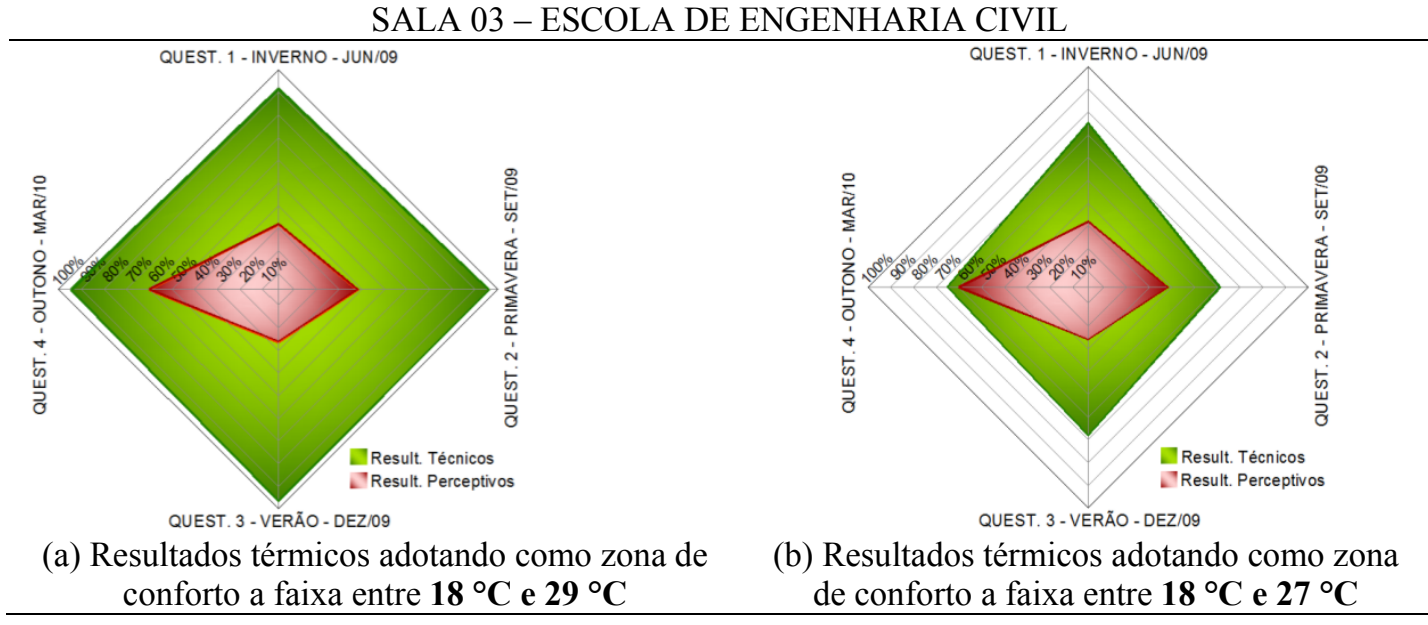

Figura 27 - Gráficos comparativos entre a percepção dos usuários e os dados técnicos de temperatura na sala 3 da EEC

\section{SALA 6 - ESCOLA DE ENGENHARIA CIVIL}

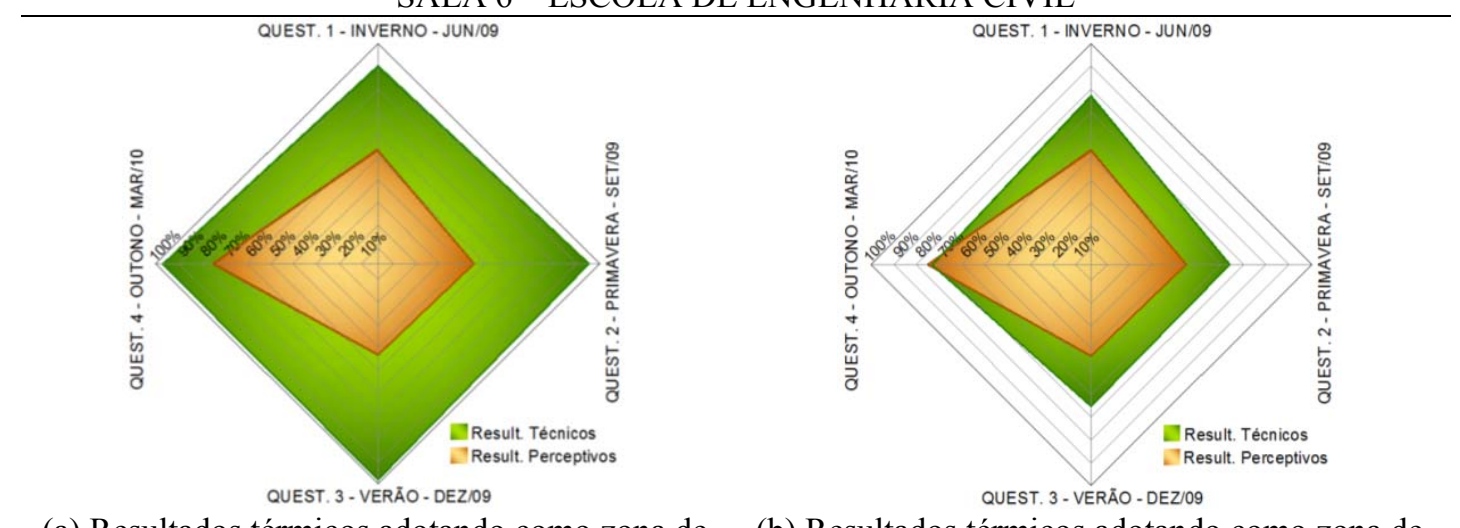

(a) Resultados térmicos adotando como zona de conforto a faixa entre $18^{\circ} \mathrm{C}$ e $29^{\circ} \mathrm{C}$

(b) Resultados térmicos adotando como zona de conforto a faixa entre $18^{\circ} \mathrm{C}$ e $27^{\circ} \mathrm{C}$

Figura 28 - Gráficos comparativos entre a percepção dos usuários e os dados técnicos de temperatura na sala 6 da EEC

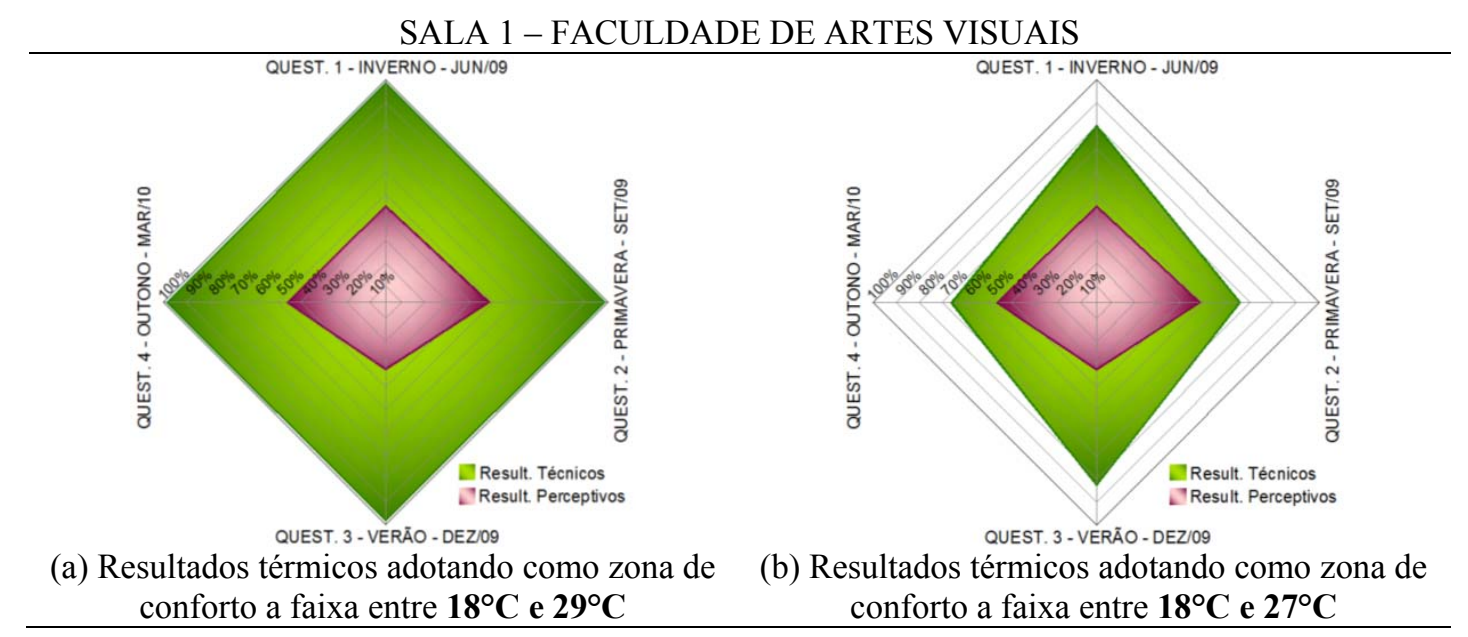

Figura 29 - Gráficos comparativos entre a percepção dos usuários e os dados técnicos de temperatura na sala 1 da FAV 


\section{SALA 3 - FACULDADE DE ARTES VISUAIS}

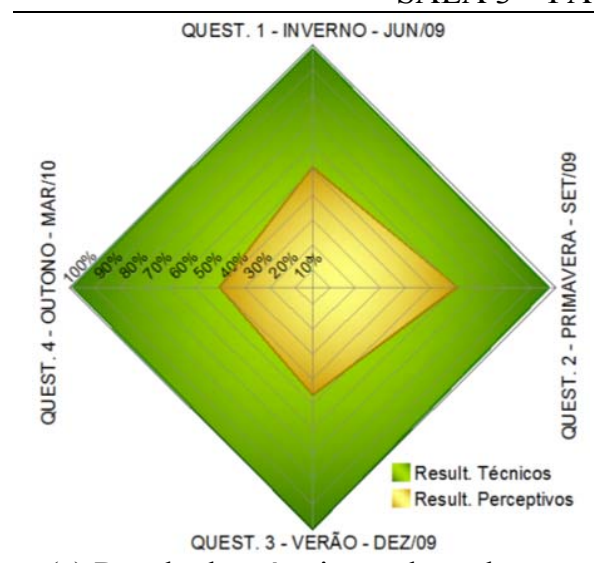

(a) Resultados térmicos adotando como zona de conforto a faixa entre $18^{\circ} \mathrm{C}$ e $29^{\circ} \mathrm{C}$

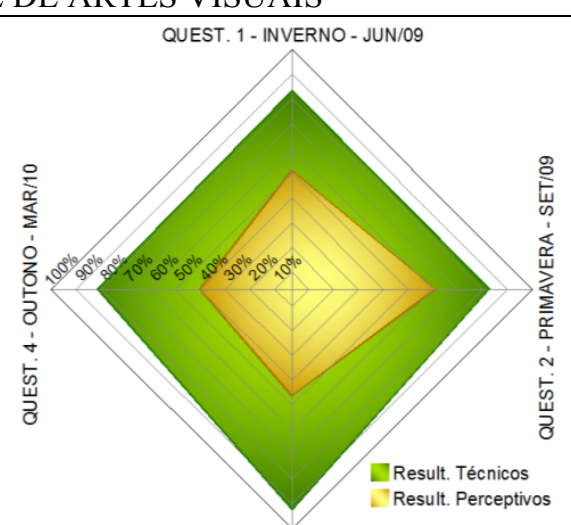

QUEST. 3 - VERÃO - DEZ/O9

(b) Resultados térmicos adotando como zona de conforto a faixa entre $18^{\circ} \mathrm{C}$ e $27^{\circ} \mathrm{C}$

Figura 30 - Gráficos comparativos entre a percepção dos usuários e os técnicos de temperatura na sala 3 da FAV

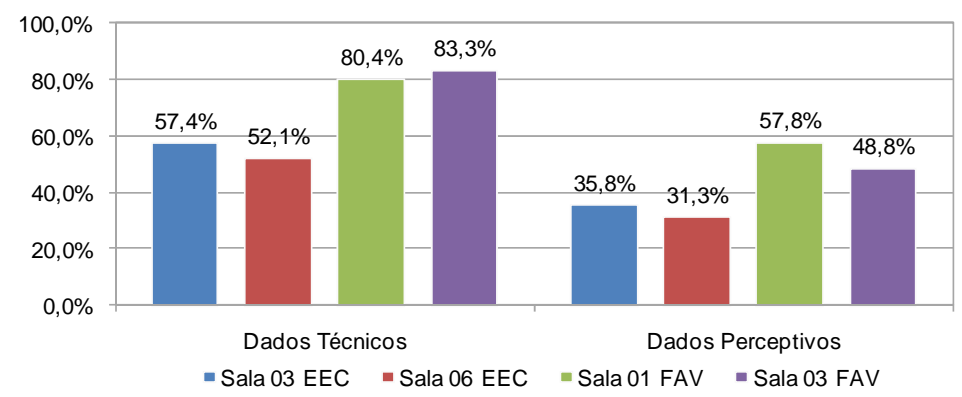

Figura 31 - Gráficos comparativos entre a percepção dos níveis de satisfação dos usuários e os dados técnicos quanto às condições acústicas

Se for tomada a sugestão da ISO 7730 (INTERNATIONAL..., 2005) para a determinação do conforto térmico a partir da percentagem de pessoas insatisfeitas, conclui-se que nenhuma das salas possui mais de $90 \%$ de pessoas satisfeitas, o que significa que, por essa metodologia, essas salas não apresentam conforto térmico. Entretanto, os dados técnicos da semana de aplicação dos questionários, bem como de todo o período avaliado, mostram que em mais de $90 \%$ do tempo as salas poderiam ser consideradas confortáveis do ponto de vista técnico. Essa percentagem diminui para menos de $60 \%$ quando a temperatura máxima da zona de conforto é reduzida para $27{ }^{\circ} \mathrm{C}$. Entretanto, ainda permanece acima do percentual de usuários satisfeitos.

\section{Medições acústicas}

Para avaliar a percepção dos usuários em relação ao conforto acústico, foram tomadas as respostas dos usuários às questões 15, 16 e 19 nos quatro questionários aplicados ao longo do ano. Isso porque se parte do pressuposto de que o conforto acústico seja pouco influenciado pelas estações do ano. Apenas os usuários cuja totalidade de respostas encontrava-se no nível satisfeito foram considerados como usuários satisfeitos do ponto de vista acústico. O percentual técnico de satisfação foi definido pela relação entre a quantidade de leituras inferiores ao valor limite adotado $(50 \mathrm{~dB}$ em ambientes internos e $55 \mathrm{~dB}$ na área externa) e a quantidade total de leituras realizadas.

Dentro dessas limitações, têm-se os resultados ilustrados na Figura 30, onde se nota que, nas salas de aula da EEC, tanto os dados técnicos quanto os dados perceptivos apresentaram níveis de satisfação inferiores aos da FAV. Isso tem a provável influência do fato de a EEC estar em contato com níveis elevados de ruído advindo principalmente do tráfego de veículos na via próxima, o que gera um perceptível incômodo para os usuários das salas. Esse desconforto é acentuado principalmente se as janelas estiverem abertas, o que ocorre na maior parte do tempo, devido às temperaturas geradoras de desconforto por calor. 
O contexto da FAV é diferenciado, pois os ruídos detectados são provenientes de atividades originadas na própria escola. Essas características são refletidas nos dados técnicos (Figura 31). Cerca de $80 \%$ dos dados estão na zona de conforto. No entanto, os usuários apresentaram algumas reclamações em relação aos ruídos originários da cantina e das áreas de circulação, o que refletiu no menor nível de conforto acústico apontado pelos usuários.

\section{Conclusões}

A partir dos dados técnicos obtidos nesta pesquisa, conclui-se que ambas as edificações possuem deficiências em termos de desempenho ambiental, em muito acentuadas por elementos arquitetônicos, que influem de forma positiva em uma modalidade de conforto e negativa em outra. A principal deficiência observada foi do ponto de vista do conforto lumínico, o qual foi bastante prejudicado em função da escolha de elementos arquitetônicos que visaram à melhoria apenas do conforto térmico.

Por outro lado, as escolhas arquitetônicas parecem ter respondido de forma mais adequada às solicitações térmicas ocorrentes na região, proporcionando adequado conforto térmico das salas de aula, haja vista os resultados das medições técnicas, que mostram que elas se encontram na zona de conforto térmico $\left(18{ }^{\circ} \mathrm{C}\right.$ a $\left.29{ }^{\circ} \mathrm{C}\right)$ em mais de $90 \%$ do ano. Isso ocorreu, inclusive, na edificação da FAV, onde as paredes não atendem aos critérios de transmitância térmica, atraso térmico e fator solar especificados pela NBR 15220-3 (ABNT, 2005b). Tal observação demonstra a importância da escolha de elementos arquitetônicos que possam suprir a deficiência de sistemas construtivos porventura utilizados.

Apesar desse aparente conforto térmico constatado pelos dados técnicos, quando eles são confrontados com os resultados da percepção dos usuários, notase que o percentual de usuários satisfeitos é bem inferior a $90 \%$, levando a crer que essas salas não são julgadas confortáveis do ponto de vista térmico. Na tentativa de obter-se uma correlação entre os resultados das duas metodologias, o limite superior da zona de conforto foi reduzido para 27 ${ }^{\circ} \mathrm{C}$. Com isso, houve melhor ajuste entre os dados de medições técnicas e de avaliação de percepção de conforto pelos usuários, tendo-se detectado uma redução da quantidade de horas em que as salas encontravam-se na zona de conforto, que ficou em um valor próximo a $60 \%$ do total de horas registradas. Dessa forma, houve maior aproximação com o percentual de usuários satisfeitos nas salas analisadas.
Da análise dos resultados da percepção dos usuários com relação ao conforto lumínico, podese concluir que as salas analisadas não são confortáveis. Essa conclusão está de acordo com a obtida a partir dos dados técnicos. Entretanto, apesar de as duas técnicas corroborarem a mesma conclusão, o nível de usuários satisfeitos com a iluminação natural dessas salas é muito maior que a porcentagem de pontos constatados como provendo uma adequada iluminação natural. Isso leva a crer que a forma como as salas estejam sendo utilizadas, isto é, com o uso de retroprojetor para as aulas ministradas, pode influenciar a percepção do usuário com relação a seu ajuste a uma condição de conforto lumínico.

Uma discrepância similar, agora entre a percepção dos usuários e os dados técnicos, foi observada com relação ao conforto acústico. Neste caso, entretanto, os dados técnicos são preliminares e carecem de um maior aprofundamento. Apesar disso, pode-se constatar que ambas as metodologias utilizadas indicaram baixo nível de conforto acústico nas salas da EEC, devido ao tráfego urbano em sua proximidade. $\mathrm{O}$ distanciamento da edificação da via ruidosa, notoriamente, não propicia um nível de conforto acústico adequado às salas de aula, principalmente nas salas com janelas voltadas diretamente para a via. Este pode não ter sido um problema quando da construção da edificação, há várias décadas (quando o fluxo de tráfego nas vias próximas era consideravelmente mais baixo), já que a edificação conta com grandes aberturas para iluminação e ventilação, maiores que o atualmente exigido no código de edificações de Goiânia, mas, certamente, passou a constituir um incômodo com o aumento do tráfego urbano na cidade. Soluções arquitetônicas que visem criar uma barreira acústica devem ser adotadas nas novas edificações escolares da Universidade, em especial naquelas situadas próximo ao centro urbano.

Ressalta-se que as avaliações técnicas realizadas, em especial quanto aos confortos térmico e acústico, foram limitadas. Alguns fatores relevantes para o conforto térmico, como o uso de oportunidades adaptativas para ampliar a faixa de conforto, não foram considerados. Apesar disso, essas técnicas foram compatíveis com o objetivo da pesquisa, de apresentar uma visão holística dos três tipos de conforto, buscando avaliar o conforto ambiental da edificação.

Finalmente, dentro dessa visão holística que buscou orientar a pesquisa, pode-se concluir que há necessidade de maiores estudos para identificar e quantificar as interferências de uma modalidade de conforto sobre as demais, de modo a obter-se uma metodologia adequada para determinar um 
nível de conforto ambiental "balanceado" de uma edificação. Nesse sentido, metodologias baseadas na avaliação da percepção dos usuários certamente serão de fundamental importância, por se constituírem em uma técnica simples de ser aplicada. Entretanto, novos estudos ainda necessitam ser realizados, de forma a determinarse uma correlação mais bem ajustada entre os limites de conforto definidos pelas normas técnicas e aqueles avaliados a partir da satisfação do usuário.

\section{Referências}

ASSOCIAÇÃO BRASILEIRA DE NORMAS TÉCNICAS. NBR 5413: iluminância de Interiores. Rio de Janeiro, 1992.

ASSOCIAÇÃO BRASILEIRA DE NORMAS TÉCNICAS. NBR 10152: níveis de ruído para conforto acústico. Rio de Janeiro, 1987.

ASSOCIAÇÃO BRASILEIRA DE NORMAS TÉCNICAS. NBR 15215-4: iluminação natural: Parte 4 - Verificação experimental das condições de iluminação interna de edificações - Método de medição. Rio de Janeiro, 2005a.

\section{ASSOCIAÇÃO BRASILEIRA DE NORMAS}

TÉCNICAS. NBR 15220-3: desempenho térmico de edificações: Parte 3 - Zoneamento bioclimático brasileiro e diretrizes construtivas para habitações unifamiliares de interesse social. Rio de Janeiro, 2005b.

BECKER, R.; GOLDBERG, I.; PACIUK, M. Improving Energy Performance of School Buildings While Ensuring Indoor Air Quality Ventilation. Building and Environment, Lausanne, v. 42, n. 9, p. 3261-3276, 2007.

BISTAFA, S. R. Acústica Aplicada ao Controle de Ruído. São Paulo: Eduardo Blücher, 2006. 368 p.

CENTRO DE GESTÃO DO ESPAÇO FÍSICO DA UNIVERSIDADE FEDERAL DE GOIÁS. Projeto Completo da Escola de Engenharia da Civil, UFG. Goiânia: UFG, 2008.

CORBELlA, O.; YANNAS, S. Em Busca de Uma Arquitetura Sustentável Para os Trópicos. Rio de Janeiro: Revan, 2003.

FERNANDES, A. M. C. P. Clima, Homem e Arquitetura. Goiânia: Trilhas Urbanas, 2006.

FRANSSON, N.; VÄSTFJÄLL, D.; SKOOG, J. In Search of the Comfortable Indoor Environment: a comparison of the utility of objective and subjective indicators of indoor comfort. Building and Environment, v. 42, n. 5, p. 1886-1890, 2007.
GIVONI, B. Climate Considerations in Building and Urban Design. New York: Van Nostrand Reinhold, 1998.

GOOGLE. Google Earth 6. Disponível em: $<$ http://earth.google.com/intl/pt/>. Acesso em: 17 mar. 2012.

IRVINE, K. et al. Green Space, Soundscape and Urban Sustainability: an interdisciplinary, empirical study. Local Environment, v. 14, n. 2, p. $155-172,2009$.

\section{INTERNATIONAL ORGANIZATION FOR}

STANDARDIZATION. ISO 7730: ergonomics of the thermal environment: analytical determination and interpretation of thermal comfort using calculation of the PMV and PPD indices and local thermal comfort criteria. Switzerland, 2005.

KOWALTOWSKI, D. C. C. K. et al. Melhoria do Conforto Ambiental em Edificações Escolares na Região de Campinas. In: ENCONTRO NACIONAL DE CONFORTO NO AMBIENTE CONSTRUÍDO, 2., Fortaleza, 1999. Anais... Fortaleza: ANTAC, 1999.

\section{LABORATÓRIO DE EFICIÊNICA} ENERGÉTICA EM EDIFICAÇÕES.

Transmitância Versão 1.0. Disponível em: $<$ http://www.labeee.ufsc.br/software/transmitancia .html>. Acesso em: 17 mar. 2012.

LAMBERTS, R; XAVIER, A. Apostila de Conforto Térmico e Stress Térmico. Florianópolis: Laboratório de Eficiência Energética em Edificações/Universidade Federal de Santa Catarina, 2002.

LI, D.; TSANG, E. An Analysis of Daylighting Performance for Office Buildings in Hong Kong. Building and Environment, v. 43, n. 9, p. 14461458, 2008.

LOSSO, M. A. F. Qualidade Acústica de Edificações Escolares em Santa Catarina: avaliação e elaboração de diretrizes para projeto e implantação. 168 f. Florianópolis, 2003.

Dissertação (Mestrado em Engenharia Civil) Programa de Pós-graduação em Engenharia Civil, Universidade Federal de Santa Catarina, Florianópolis, 2003.

MENDELL, M. J.; HEATH, G. A. Do Indoor Pollutants and Thermal Conditions in Schools Influence Student Performance? A critical review of literature. Indoor Air: International Journal of Indoor Environment and Health, v. 15, n. 1, p. 27-52, 2005. 
OCHOA, J. H. Análise do Conforto Ambiental em Salas de Aula da Universidade Federal de Goiás. 247f. Goiânia, 2010. Dissertação (Mestrado em Engenharia Civil) - Programa de Pósgraduação em Geotecnia e Construção Civil, Universidade Federal de Goiás, Goiânia, 2010.

ORNSTEIN, S.; ROMERO, M. Avaliação PósOcupação do Ambiente Construído. São Paulo: Studio Nobel, 1992.

ROAF, S.; FUENTES, M.; THOMAS, S.

Ecohouse: a casa ambientalmente sustentável. Tradução Alexandre Salvaterra. Porto Alegre: Bookman, 2006.

SCHMID, A. L. A Idéia de Conforto: reflexões sobre o ambiente construído. Curitiba: Pacto Ambiental, 2005.

SZOKOLAY, S. V. Environmental Science Handbook. Lancaster: The Construcion Press, 1980.
THEODOSIOU, T. G.; ORDOUMPOZANIS, K. T. Energy, Comfort and Indoor Air Quality in Nursery and Elementary School Buildings in the Cold Climatic Zone of Greece. Energy and Buildings, v. 40, n. 12, p. 2207-2214, 2008.

XAVIER, A. A. P. Condições de Conforto Térmico Para Estudantes de $2^{\circ}$ Grau na Região de Florianópolis. 209 f. Florianópolis, 1999. Dissertação (Mestrado em Engenharia Civil) Programa de Pós-graduação em Engenharia Civil, Universidade Federal de Santa Catarina, Florianópolis, 1999.

\section{Agradecimentos}

Os autores agradecem o apoio financeiro da Capes, por meio do programa Procad/Novas Fronteiras 2007, que possibilitou o intercâmbio entre instituições. Também agradecem o apoio financeiro da Finep, por meio da Chamada Pública MCT/Finep/FNDCT - Promove - Engenharia no Ensino Médio 05/2006, o qual possibilitou a aquisição dos equipamentos utilizados na pesquisa.

Revista Ambiente Construído

Associação Nacional de Tecnologia do Ambiente Construído

Av. Osvaldo Aranha, 99 - 3o andar, Centro

Porto Alegre - RS - Brasil

CEP $90035-190$

Telefone: +55 (51) 3308-4084

Fax: +55 (51) 3308-4054

www. seer. ufrgs. br/ ambienteconstruido

E-mail: ambienteconstruido@ufrgs.br 